\title{
Application of Thermodynamics and Kinetics in Materials Engineering
}

Lin $\mathrm{Li}$

Additional information is available at the end of the chapter

http://dx.doi.org/10.5772/50335

\section{Introduction}

\subsection{Background}

During the last 30 years, there was a surge for coupling thermodynamics and phase diagrams in the field of material science. Many large programmers as well as the exploring of versatile solution models, the description of the magnetism energy of elements and solutions, etc. were developed. Thermo-Calc, as one of the most successful commercial software package for calculation of phase equilibrium from a broad database, offered appropriate guidance for the materials study and reduced the amount of experiments. For example, the slag database in this commercial software package could be used for predicting the composition of oxide and sulphide inclusion formed during the deoxidation and solidification process with a specific multiphase equilibrium calculation.

However, there was still far from much work in the field of prediction or estimation based on the principles of thermodynamics and kinetics for the practical processes in mass production or the designing of kinds of materials. This chapter aims at introducing some computational results on the designing of advanced materials.

\section{Research and development on Transformation Induced Plasticity (TRIP) steel}

\subsection{TRIP steel containing Al}

Low carbon low alloy TRIP steel receives significant interest in automobile industry since it offers excellent combination of high strength and formability for stretch forming or deep drawing applications. The high formability in this steel is attributed to the transformation induced plasticity of retained austenite. The amount and stability of retained austenite are the key factors, which influences the transformation behavior during straining. 
As well known high Si content suppresses the formation of cementite during the bainitic transformation and it leads to an increase of the stability and the amount of retained austenite. However, high Si content might cause problems in steel production such as strong oxide layer, poor surface characteristics and low coat-ability. This leads to galvanizing problems.

Therefore, efforts are made to improve the composition concept, say, the substitution of Si by other elements which might not spoil surface quality. In the first phase, different amount of $\mathrm{Al}$ is added as an alternative to the steel to substitute for $\mathrm{Si}^{[1]}$. In order to understand the complex effects of $\mathrm{Al}$, Si in TRIP steel, many samples of different composition are prepared. As an example, the overall compositions of five samples of them are listed in Table $1^{[2]}$, where steel no.2, 4, 11 with high $\mathrm{Al}$ content are designed as the galvanizing base material with high requirement on elongation, steel no.5 and 10 are compared materials.

\begin{tabular}{|c|c|c|c|c|c|c|}
\hline No. & $\mathrm{C}$ & $\mathrm{Mn}$ & $\mathrm{Si}$ & $\mathrm{Al}$ & $\mathrm{P}$ & $\mathrm{Fe}$ \\
\hline 2 & 0.18 & 1.56 & 0.02 & 1.73 & 0.017 & Bal. \\
\hline 4 & 0.18 & 1.65 & 0.45 & 1.01 & 0.015 & Bal. \\
\hline 5 & 0.21 & 1.41 & 1.07 & 0.32 & 0.017 & Bal. \\
\hline 10 & 0.19 & 1.47 & 0.87 & 0.33 & 0.024 & Bal. \\
\hline 11 & 0.19 & 1.47 & 0.22 & 0.94 & 0.024 & Bal. \\
\hline
\end{tabular}

Table 1. Compositions of TRIP steels (in wt- $\%)^{[2]}$

Simulation of the inter-critical annealing at $780^{\circ} \mathrm{C}$ of steels is performed with Thermo-calc and its database. The Gibbs free energy of an arbitrary phase is listed as:

$$
G_{m}=\sum_{I 0} P_{I 0}(Y) \cdot G_{I 0}^{O}+R T \sum_{S} N^{S} \sum_{i} y_{i}^{S} \ln y_{i}^{S}+\sum_{Z>0} \sum_{I Z} P_{I Z}(Y) \cdot L_{I Z}
$$

The first summation in equation (1) represented the standard energy, the second the mixing entropy and the third the excess Gibbs energy.

The results ${ }^{[2]}$ (see in Table 2) show steel no.2 and 4 must have good plasticity and fairly good strength since both have high volume fraction of $\alpha$ phase (ferrite), though the $\gamma$ phase (austenite) is less, it can still induce some bainite transformation in the low temperature and raise the strength of the steels. From Table $2^{[2]}$, it seems steel no.11 may have good combination and highest value of strength and plasticity since it possesses much higher $\gamma$ phase than steel no. 2 and 4 and also the high $\alpha$ phase volume fraction which is favor to ductility.

Simulation of the continuous annealing process in the inter-critical temperature is performed with Dictra software package ${ }^{[2]}$. The concentration profiles in the equilibrium phases are estimated with the 'number-fixed frame of reference' with respect to the substitutional elements as follows:

$$
\sum j_{k}^{\alpha}=\sum j_{k}^{\beta}=0
$$

where $j$ is flux and $k$ was substitutional. For crystalline phases of iron based alloys, the vacancy exchange mechanism of diffusion was predominant, thus, in the lattice fixed frame of reference, the diffusion flux of component $k$ could be written as: 


$$
\tilde{J}_{k}=-x_{k} \Omega_{k} \nabla \mu_{k}
$$

where $x_{k}$ was the mole fraction of $k, \Omega_{k}$ represented mobility and $\nabla \mu_{k}$ the gradient of chemical potential of element $k$.

Employing a coupled thermodynamic/kinetic method for the solution of the related equations, the concentration profile of the various elements is obtained. Some of the obtained diffusion data are used to guide the processes in mill.

Mechanical properties of the produced TRIP steels are shown in Fig.1[2], where all the steels are inter-critical annealed at $780^{\circ} \mathrm{C}$ for five minutes and then cooled to different temperatures in the bainite transformation zone.

\begin{tabular}{|c|c|c|c|c|c|c|c|c|}
\hline $\begin{array}{c}\text { steel } \\
\text { no. }\end{array}$ & phase & $\mathrm{C}$ & $\mathrm{Mn}$ & $\mathrm{Si}$ & $\mathrm{Al}$ & $\mathrm{P}$ & $\alpha \%$ & $\gamma \%$ \\
\hline \multirow{2}{*}{2} & $\alpha$ & $2.66 \mathrm{E}-4$ & $1.18 \mathrm{E}-2$ & $1.96 \mathrm{E}-4$ & $2.00 \mathrm{E}-2$ & $2.05 \mathrm{E}-4$ & \multirow{2}{*}{73.4} & 26.6 \\
\cline { 2 - 8 } & $\gamma$ & $6.07 \mathrm{E}-3$ & $2.61 \mathrm{E}-2$ & $2.10 \mathrm{E}-4$ & $9.66 \mathrm{E}-3$ & $7.19 \mathrm{E}-5$ & & \\
\hline \multirow{2}{*}{4} & $\alpha$ & $1.71 \mathrm{E}-4$ & $1.14 \mathrm{E}-2$ & $4.58 \mathrm{E}-3$ & $1.24 \mathrm{E}-2$ & $1.98 \mathrm{E}-4$ & \multirow{2}{*}{63.4} & \multirow{2}{*}{36.6} \\
\cline { 2 - 8 } & $\gamma$ & $4.65 \mathrm{E}-3$ & $2.55 \mathrm{E}-2$ & $4.36 \mathrm{E}-3$ & $6.00 \mathrm{E}-3$ & $6.62 \mathrm{E}-5$ & & \\
\hline \multirow{2}{*}{5} & $\alpha$ & $1.30 \mathrm{E}-4$ & $8.57 \mathrm{E}-3$ & $1.16 \mathrm{E}-2$ & $4.22 \mathrm{E}-3$ & $2.52 \mathrm{E}-4$ & \multirow{2}{*}{51.1} & 48.9 \\
\cline { 2 - 8 } & $\gamma$ & $4.18 \mathrm{E}-3$ & $2.00 \mathrm{E}-2$ & $9.71 \mathrm{E}-3$ & $2.12 \mathrm{E}-3$ & $8.32 \mathrm{E}-5$ & & \\
\hline \multirow{2}{*}{10} & $\alpha$ & $1.20 \mathrm{E}-4$ & $9.04 \mathrm{E}-3$ & $9.40 \mathrm{E}-3$ & $4.32 \mathrm{E}-3$ & $3.52 \mathrm{E}-4$ & 52.4 & 47.6 \\
\cline { 2 - 7 } & $\gamma$ & $3.88 \mathrm{E}-3$ & $2.10 \mathrm{E}-2$ & $7.92 \mathrm{E}-3$ & $2.17 \mathrm{E}-3$ & $1.16 \mathrm{E}-4$ & & \\
\hline \multirow{2}{*}{11} & $\alpha$ & $1.65 \mathrm{E}-4$ & $9.77 \mathrm{E}-3$ & $2.27 \mathrm{E}-3$ & $1.21 \mathrm{E}-2$ & $3.38 \mathrm{E}-4$ & 54.5 & 45.5 \\
\cline { 2 - 7 } & $\gamma$ & $3.99 \mathrm{E}-3$ & $2.06 \mathrm{E}-2$ & $2.12 \mathrm{E}-3$ & $6.15 \mathrm{E}-3$ & $1.22 \mathrm{E}-4$ & & \\
\hline
\end{tabular}

Table 2. Calculated equilibrium compositions (in wt- $\%$ ) at $780^{\circ} \mathrm{C}$ and corresponding vol. $\%$ of $\alpha$ and $\gamma$ phases $^{[2]}$

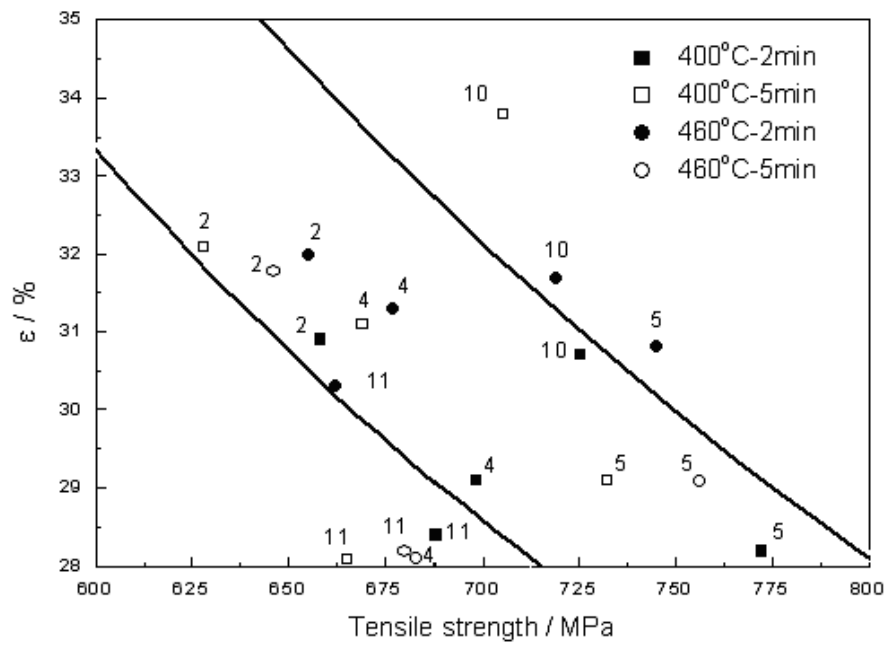

Figure 1. Mechanical properties of the various TRIP -aided steels after different heat treatment ${ }^{[2]}$ 
Mechanical properties of steel no. 2 and 4 are in accordance with thermodynamic estimation except steel no.11 which does not show high strength and elongation rate as expected. Kinetic calculation results in Fig.2-5 explain that phenomena: after inter-critical annealing, the distribution of $\mathrm{C}$ and $\mathrm{Mn}$ in steels no.5, 10 and 11 does not exhibit substantial difference. However, high Si concentrates in the $\gamma$ phase of steels no.5 and 10 while high $\mathrm{Al}$ in steel no.11. It follows from that result $\mathrm{Al}$ can substitute for $\mathrm{Si}$ to induce TRIP effect but its function is not as strong as Si.
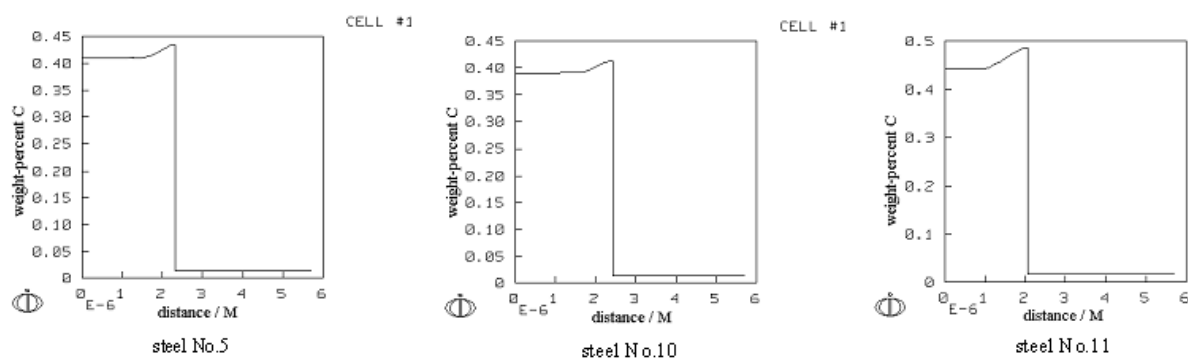

Figure 2. Concentration profile of $\mathrm{C}$ at the $\alpha / \gamma$ interface during inter-critical annealing at $780^{\circ} \mathrm{C}$ of the steel No.5, No.10 and No.11

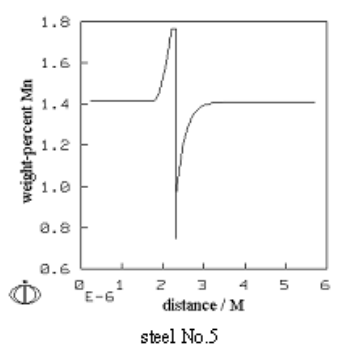

CELL H1

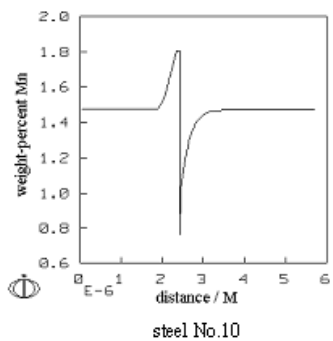

CELL $* 1$

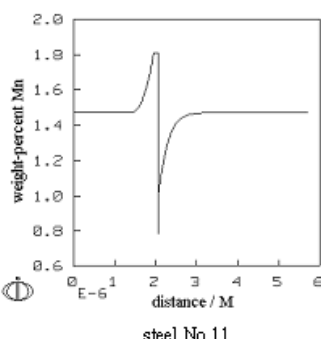

CELL \# 1

Figure 3. Concentration profile of $\mathrm{Mn}$ at the $\alpha / \gamma$ interface during inter-critical annealing at $780^{\circ} \mathrm{C}$ of the steel No.5, No.10 and No.11
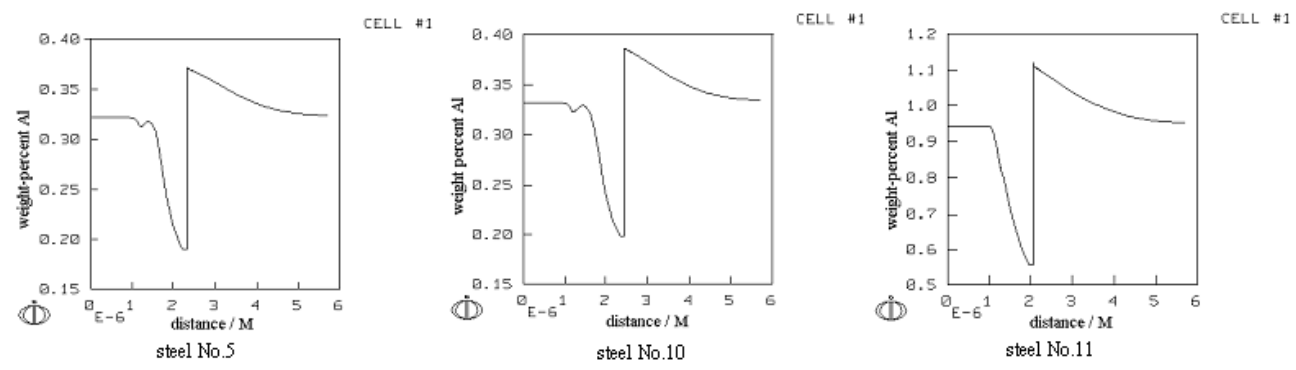

Figure 4. Concentration profile of $\mathrm{Al}$ at the $\alpha / \gamma$ interface during inter-critical annealing at $780^{\circ} \mathrm{C}$ of the steel No.5, No.10 and No.11 

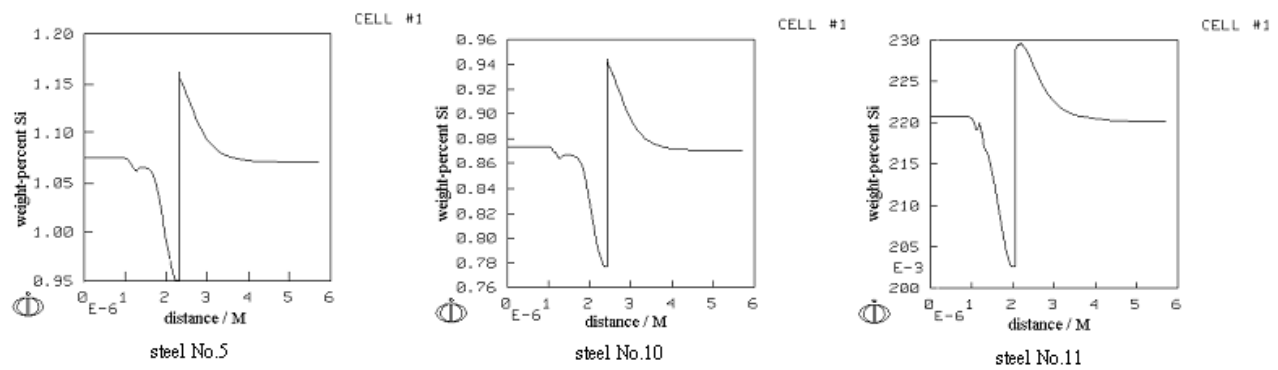

Figure 5. Concentration profile of $\mathrm{Si}$ at the $\alpha / \gamma$ interface during inter-critical annealing at $780^{\circ} \mathrm{C}$ of the steel No.5, No.10 and No.11

Different from steels no.5 and 10, steels no.2, 4 and 11 therefore possess both super coatability and satisfactory mechanical properties due to their high $\mathrm{Al}$ content. These three steels mentioned above were adopted and produced in ThyssenKrupp stahl and Voest-Alpine Arcelor and the sheet steels were manufactured as important structural parts, e.g., reinforcement A-pillars and reinforcement B-pillars in FIAT and PORSCHE, which are the pioneers in the organization of ULSAB (Ultra-Light Steel Auto Body).

\subsection{TRIP steel containing $P$}

As stated above, in order to replace Si partially and/or totally, efforts were made with $\mathrm{Al}$ instead ${ }^{[1,2]}$. The substitution was successful but only limited at low $\mathrm{Al}$ content. Side effect of high $\mathrm{Al}$ content in the steel is estimated that it may cause clogging during continuous casting due to precipitation of aluminum oxide ${ }^{[3]}$. Searching for the other effective element to substitute for $\mathrm{Si}$ was then triggered. In the periodic table of elements, $\mathrm{Al}, \mathrm{Si}$, and $\mathrm{P}$ are located nearby in the same period, these elements have similar electronic structures and may have similar properties. This comes true especially to Si and P since they both are semimetals. It is then natural to consider P as another substitute for Si. P can, on one hand, depress the carbon activity in cementite, prevent cementite precipitation and increase the stability of austenite. On the other hand, this element has a strong tendency to segregate at grain boundary and to induce cold brittleness. Segregation formulation was developed by Guttmann and Mclean in a ternary system (Fe, M, I) ${ }^{[4]}$ based on the sublattice model in melt salts and stoichiometric phases contributed by Hillert et al[5]. Li et al. extended the segregation equation into a five-element system ${ }^{[6]}$, and generalized it into a multicomponent system as ${ }^{[7]}$ :

$$
\begin{aligned}
y_{I}^{g} / y_{V}^{g}= & \left(y_{I}^{B} / y_{V}^{B}\right) \exp \left\{\left[\Delta^{0} G_{I}+1 / c^{g} \sum_{i \neq A} y_{i}^{g} \beta_{i I}^{g}-1 / c^{B} \sum_{i \neq A} y_{i}^{B} \beta_{i I}^{B}-1 / c^{g} \sum_{J \neq I} y_{J}^{g} L_{A: J I}^{g}+\right.\right. \\
& \left.\left.+1 / c^{g} \sum_{J \neq I} y_{J}^{g} L_{A: J V}^{g}+1 / c^{B} \sum_{J \neq I} y_{J}^{B} L_{A: J I}^{B}-1 / c^{B} \sum_{J} y_{J}^{B} L_{A: J V}^{B}\right] / R T\right\}
\end{aligned}
$$




$$
\begin{aligned}
y_{M}^{g} / y_{A}^{g}= & \left(y_{M}^{B} / y_{A}^{B}\right) \exp \left\{\left[\Delta^{0} G_{M}+1 / a^{g} \sum y_{I}^{g} \beta_{M I}^{g}-1 / a^{B} \sum y_{I}^{B} \beta_{M I}^{B}-1 / a^{g} \sum_{i \neq M} y_{i}^{g} L_{i: M V}^{g}+\right.\right. \\
& \left.\left.+1 / a^{B} \sum_{i \neq M} y_{i}^{B} L_{i: M V}^{B}+1 / a^{B} \sum_{i \neq A} y_{i}^{g} L_{A i: V}^{g}-1 / a^{B} \sum_{i \neq A} y_{i}^{B} L_{A i: V}^{B}\right] / R T\right\}
\end{aligned}
$$

where variable $y$ indicates site fraction in sublattice, $g$ grain boundary, $B$ matrix, $V$ vacancy, $A$ base metal, $J$ and $I$ represent impurity, $i$ and $M$ metal element, $c$ and $a$ fraction of sites available in grain boundary or matrix, $\Delta^{0} G_{I}$ and $\Delta^{0} G_{M}$ are the intrinsic segregation Gibbs free energy of impurity $I$ and metal element $M, L_{A: I I}^{B(g)}$ stands for the interaction energy between $J$ and $I$ in one sublattice when another sublattice is fully occupied by element $A, \beta_{M I}^{B(g)}$ means the interaction energy between elements in different sublattices. Following references $[7,8]$, assuming that interaction energy keeps the same on grain boundaries and in matrix and omitting the interaction between impurities and vacancy and between metal element and iron, a series of parameters ${ }^{[7,8]}$ can be listed as follows: $a^{g}=c^{g}=0.5, a^{B}=0.75, c^{B}=0.25, \Delta^{0} G_{P}=47 \mathrm{KJ} / \mathrm{mol}, \Delta^{0} G_{M n}=8 \mathrm{KJ} / \mathrm{mol}, \beta_{M n P}=12.5$ $\mathrm{KJ} / \mathrm{mol}, L_{F e: P C}=-9 \mathrm{KJ} / \mathrm{mol}$. With all the data stated above and the composition of an assumed steel with enough high phosphorus $(\mathrm{C}=0.15 \%, \mathrm{Mn}=1.6 \%, \mathrm{Si}=0.3 \%, \mathrm{P}=0.07 \%)$, the equilibrium segregation amount of phosphorus on grain boundaries at $400^{\circ} \mathrm{C}$ is calculated as $32 \%\left[{ }^{[9]}\right.$, which is a value high enough to cause temper brittleness.

The soaking temperature at the over-aging process of cold-rolled TRIP steel is set in the temperature range from 350 to $480^{\circ} \mathrm{C}$. However, the soaking time is quite short, normally for 3 5 min, being far from equilibrium condition. Thus, the estimated equilibrium segregation amount of phosphorus is not suitable in describing the over-aging process of TRIP steels.

Based on Mclean contribution with his kinetic approach for a binary system ${ }^{[10]}$, the amount of segregative element on grain boundaries can be expressed as:

$$
\left(y_{i}^{\phi}(t)-y_{i}^{\phi}(0)\right) /\left(y_{i}^{\phi}-y_{i}^{\phi}(0)\right) \cong 2\left(X_{i}^{\alpha} / y_{i}^{\phi} d\right)\left(D_{i} t / \pi\right)^{1 / 2}
$$

where $y_{i}^{\phi}(t)$ is the grain boundary coverage of element $i$ at time $t, y_{i}^{\phi}(0)$ is its initial value and $y_{i}^{\phi}$ the equilibrium value. $D_{i}$ is the bulk diffusion coefficient of $i, d$ the grain boundary thickness and $X_{i}^{\alpha}$ the mole fraction of $i$ in matrix. Taking $d=10^{-7} \mathrm{~cm}$ as usual, $t$ $=5 \mathrm{~min}=300 \mathrm{sec}$ and $T=673 \mathrm{~K}$ according to the actual process condition, $X_{P}^{\alpha}=1.387 \times 10^{-3}$ (i.e., $\mathrm{wt}=0.07 \%), y_{i}^{\phi}(0)=0$; according to Sundman et al, $D_{P}=3.53 \times 10^{-18[11]}$.

The segregated amount of $\mathrm{P}$ at grain boundary after soaking at $400^{\circ} \mathrm{C}$ for $300 \mathrm{~s}$ is:

$$
y_{P}^{\phi}(300 \mathrm{sec}) \cong 2\left(X_{P}^{\alpha} / d\right)\left(D_{P} t / \pi\right)^{1 / 2}=0.051 \%\left[{ }^{[9]}\right.
$$

which is a small amount and would not be of any damage in grain boundary for the TRIP steel. Mechanical properties of the designed steel were measured at low temperatures ($20^{\circ} \mathrm{C},-60^{\circ} \mathrm{C}$ ) and no substantial difference was found between the results obtained at low temperatures and room temperature ${ }^{[9]}$. Moreover, cold fracture test was taken with the structural part assembles of automobiles and no sign of cold brittleness was detected. The 
new type TRIP steel containing $\mathrm{P}$ was manufactured according to design stated above in Ansteel company group in China.

\subsection{Attractive effect of Al in TRIP steel}

Aluminum, however, if the clogging of $\mathrm{Al}_{2} \mathrm{O}_{3}$ can be efficiently prohibited through careful control in the continuous casting process, is also a good promoter of TRIP effect. The reason has been studied thermodynamically and the authors found that with the existed database the phase diagram of a steel containing certain a amount of $\mathrm{Al}$ can not be described accurately ${ }^{[12]}$ and must be revised. In their work ${ }^{[12]}$, high purity Fe (99.99 wt\%, Source), Al (99.97wt\%, Source) and C (99.99wt\%, Source) are used to prepare different composition FeAl-C alloys. Each alloy composition is checked by wet chemical analysis, as given in Table 3 . Additional annealing of encapsulated ingots is carried out at $1100^{\circ} \mathrm{C}$ for $360 \mathrm{~h}$ to reach equilibrium states and to obtain a homogeneous element distribution. To check the homogeneity of the annealed alloys, an EDX line scanning of $\mathrm{Al}$ and $\mathrm{C}$ is applied on the cross-section of the alloys showing the elements are evenly distributed in the Fe matrix. The DIL experiments are carried out in a Formaster-D dilatometer to investigate the ferrite to austenite transformation during the heating and cooling cycles and the results are also listed in Table 3.

\begin{tabular}{cccccccc}
\hline \multirow{2}{*}{ Alloy } & \multicolumn{3}{c}{ Composition $(\mathrm{wt} \%)$} & \multicolumn{3}{c}{ Experimental $\left({ }^{\circ} \mathrm{C}\right)$} & \multicolumn{2}{c}{ Calculated $\left({ }^{\circ} \mathrm{C}\right)$} \\
\cline { 2 - 8 } & $\mathrm{C}$ & $\mathrm{Al}$ & $\mathrm{Fe}$ & $\mathrm{A} 1$ & $\mathrm{~A}_{3}$ & $\mathrm{~A}_{1}$ & $\mathrm{~A}_{3}$ \\
\hline $\mathrm{C} 1$ & 0.15 & 1.57 & 98.28 & 731 & 987 & 729 & 1006 \\
$\mathrm{C} 2$ & 0.25 & 1.51 & 98.24 & 708 & 935 & 728 & 918 \\
$\mathrm{C} 3$ & 0.41 & 1.47 & 98.12 & 739 & 892 & 727 & 850 \\
$\mathrm{C} 4$ & 0.54 & 1.50 & 97.96 & 734 & 861 & 728 & 823 \\
$\mathrm{C} 5$ & 0.75 & 1.53 & 97.72 & 732 & 810 & 729 & 796 \\
$\mathrm{C} 6$ & 0.76 & 1.54 & 97.70 & 737 & 788 & 729 & 797 \\
$\mathrm{C} 7$ & 0.91 & 1.42 & 97.67 & 726 & 827 & 726 & 769 \\
$\mathrm{C} 8$ & 1.01 & 1.54 & 97.45 & 734 & 822 & 729 & 793 \\
$\mathrm{Al1}$ & 0.19 & 0.91 & 98.90 & 735 & 900 & 726 & 889 \\
$\mathrm{Al} 2$ & 0.20 & 1.13 & 98.67 & 745 & 938 & 725 & 900 \\
$\mathrm{Al} 3$ & 0.21 & 1.30 & 98.49 & 745 & 953 & 726 & 920 \\
\hline
\end{tabular}

Table 3. Compositions of the Fe-rich alloys and the transformation temperatures of the alloys obtained by DIL analysis and thermodynamic calculation[12]

With the new set of experimental data, it is possible to optimize the Fe-Al-C system in Ferich corner. The standard element reference (SER) state of $\mathrm{Fe}(\mathrm{bcc}), \mathrm{Al}$ (fcc) and $\mathrm{C}$ (graphite) is used as the reference state of the Gibbs energy as usual. The molar Gibbs energy of the ternary liquid phase is described by the Redlich-Kister polynomial [13]: 


$$
\begin{gathered}
G_{m}^{\text {liquid }}=\sum_{i=F e, A l, C} x_{i}^{0} G_{i}^{\text {liquid }}+R T \sum_{i=F e, A l, C} x_{i} \ln x_{i}+ \\
+x_{F e} x_{A l} L_{F e, A l}+x_{F e} x_{C} L_{F e, C}+x_{A l} x_{C} L_{A l, C}+x_{F e} x_{A l} x_{C} L_{F e, A l, C}
\end{gathered}
$$

Where $x_{i}$ is the mole fraction of element $i$ and ${ }^{0} G_{i}^{\text {liquid }}$ is the Gibbs energy of liquid $\mathrm{Fe}, \mathrm{Al}$ and $\mathrm{C}$. The binary parameters $L_{i, j}$ are obtained from the thermodynamic evaluation of the limiting binaries, whereas the $L_{F e}, A l, C$ is a ternary interaction parameter.

The Gibbs energy of solid phases, fcc (austenite), bcc (ferrite) and hcp in the Fe-Al-C system is described by a compound energy formalism consisting of substitutional and interstitial sublattices ${ }^{[14]}$. The Fe and $\mathrm{Al}$ substitute each other in the metal sublattice, while $\mathrm{C}$ and vacancies in the interstitial sublattice. The crystal structure is therefore modeled as $(\mathrm{Fe}, \mathrm{Al}) \mathrm{a}$ (C, Va)c. Symbols $a$ and $c$ denote the numbers of sites which is dependent on the crystal structure. Here the values of $a$ and $c$ are regarded as a = 1, c = 1, 3, and 0.5 for the fcc, bcc and hcp phases respectively. The molar Gibbs energy is expressed as:

$$
\begin{aligned}
G_{m}^{\phi} & =\sum_{i} y_{i}\left({ }^{o} G_{i: C}^{\phi} y_{C}+{ }^{o} G_{i: V a}^{\phi} y_{V a}\right)+a R T \sum_{i} y_{i} \ln y_{i}+c R T\left(y_{C} \ln y_{C}+y_{V a} \ln y_{V a}\right) \\
& +\sum_{i} \sum_{j} y_{i} y_{j}\left(y_{C} L_{i, j: C}+y_{V a} L_{i, j: V a}\right)+y_{C} y_{V a} \sum_{i} y_{i} L_{i: C, V a} \\
& +\sum_{i} \sum_{j} \sum_{k} y_{i} y_{j} y_{k}\left(y_{C} L_{i, j: C}+y_{V a} L_{i, j: V a}\right)+G_{m a g}
\end{aligned}
$$

Where $i, j=\mathrm{Fe}, \mathrm{Al}$ and $K=\mathrm{C}$ or Va. In Eq. 9, the variable $y_{i}$ is the site fraction of component $i$ in its sublattice. The components in different sublattices are separated by a colon and in one sublattice by a comma. ${ }^{\circ} \mathrm{Gi}$ Va is the Gibbs energy of pure element $i$ in a relevant nonmagnetic state and ${ }^{\circ} \mathrm{Gi}: \mathrm{C}$ is the Gibbs energy of a hypothetical non-magnetic state, where all interstitial sites are occupied by carbon. All $G$ values are given relative to the reference state. $G_{m a g}$ is the magnetic part of the Gibbs energy.

In the Fe-Al-C system, only one ternary $\mathrm{K}$ phase was reported besides the liquid, fcc, bcc and hcp phases. In this optimization, the description of the $\mathrm{K}$ phase is after the thermodynamic assessment of Kumar et al ${ }^{[15]}$.

Li et al ${ }^{[12]}$ optimized the Fe-Al-C ternary system based on the previous thermodynamic description of the $\mathrm{Fe}-\mathrm{C}, \mathrm{Fe}-\mathrm{Al}$ and $\mathrm{Al}-\mathrm{C}$ systems ${ }^{[15,16]}$ as well as the obtained DIL data ${ }^{[12]}$. Furthermore, Li et al ${ }^{[12]}$ extrapolated the thermodynamic properties of the limiting binary and ternary systems to higher order systems to construct the self-made database, especially for TRIP steels containing $\mathrm{Mn}, \mathrm{Si}, \mathrm{Al}, \mathrm{C}, \mathrm{Nb}$ and $\mathrm{V}$ as alloying elements. A calculated vertical section of the Fe-Mn-Si-Al-C system is presented in Fig. 6 for the alloys meeting very well with the experimental results.

Phase diagram of a steel with the same composition as in Fig.6 but without $\mathrm{Al}$ is calculated with the self-made database and shown in Fig.7. It is obvious that the bcc+fcc field in Fig.6 is much wider than that in Fig.7. As calculated: when at $800^{\circ} \mathrm{C}$, the carbon content in fcc phase in Fe-Mn-Si-Al-C steel is $0.476 \%$, while at $802^{\circ} \mathrm{C}$, the carbon content in fcc phase in Fe-Mn-Si- 
C steel is only $0.206 \%$. That means if soaking at the same temperature, the former dissolves much than two times carbon in the fcc phase resulting much higher stability of fcc phase and much better TRIP effect.

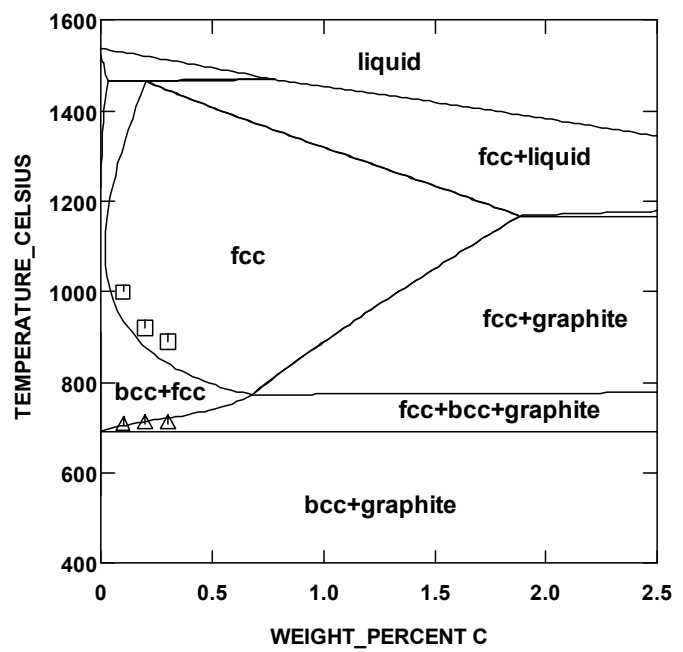

Figure 6. Extrapolated vertical section of the Fe-Mn-Si-Al-C steel with $1.60 \mathrm{wt} \% \mathrm{Mn}, 0.37 \mathrm{wt} \% \mathrm{Si}$, and $1.31 \mathrm{wt} \% \mathrm{Al}^{[12]}$.

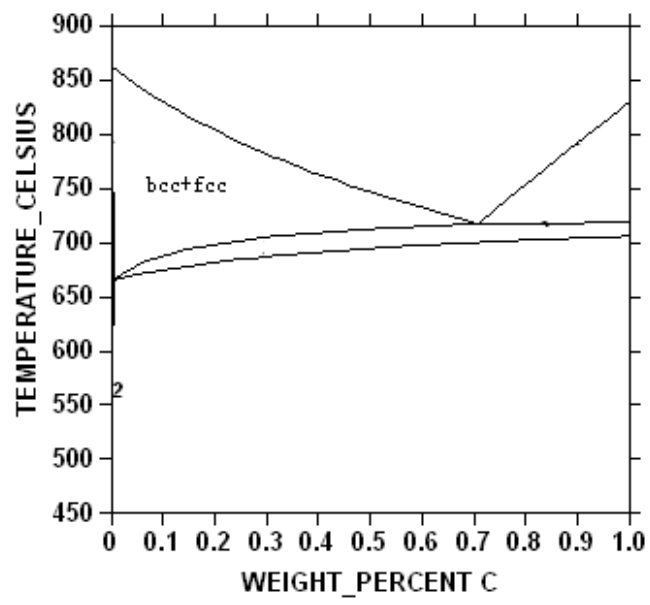

Figure 7. Phase diagram of the Fe-Mn-Si-Al-C steel with $1.60 \mathrm{wt} \% \mathrm{Mn}, 0.37 \mathrm{wt} \% \mathrm{Si}$

This new finding brings substantial improvement for the mechanical properties of TRIP steel. Following this idea, i.e, keeping reasonably high amount $\mathrm{Al}$ in the steel and treating it in an ordinary Continuous Annealing Line (CAL), a high performance TRIP steel is manufactured in modern plant, whose strength and ductility product reaches $30,000 \mathrm{MPa} \%$. It is actually the property target of a third generation steel[17]. 


\section{Research and development on large-section pre-hardened mold steel for plastic}

In large-section pre-hardened plastic mold steel, the inclusion of high alumina content is detrimental to machinability, which is considered as the most important property of mold steel for plastic. It is known that non-metallic inclusion may appear in molten steel at various stages of the refining process or during solidification. One could not analyze in situ the precipitation of inclusions at every period of steel-making by traditional experimental method. However, the effective composition regulation and suitable heat treatment during production could influence inclusion precipitation and improve the quality of the mold steel for plastic. This paragraph is designed to produce a large-section pre-hardened plastic mold steel relying on the step by step thermodynamic calculation ${ }^{[18]}$.

The SLAG database in Thermo-calc software package contributed by Gaye ${ }^{[19]}$ is a useful tool which studied the slag mixture of m oxides $\left(\left(M_{i}\right)_{u_{i}} O_{v_{i}}, \mathrm{i}=1,2, \ldots, \mathrm{m}\right)$ including two kinds of sub-lattice. One is an anionic sub-lattice filled with oxygen ions and the other is cationic sublattice filled with the cations in the decreasing order of their charge (e.g $\mathrm{Si}^{4+} \ldots \mathrm{Ca}^{2+} \ldots$ ). The structure of the melt is described in term of symmetric (i-O-i ) and asymmetric (i-O-j) cells,

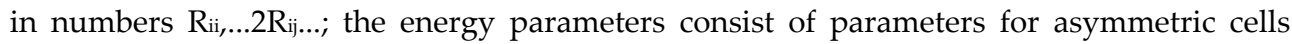
formation and parameters of interaction between cells. This simplified melt structure greatly and made it possible to describe the multi-component system in terms of only a few binary parameters. Because the formation of melt can be thought as the result of the following bond respond:

$$
(\mathrm{i}-\mathrm{O}-\mathrm{i})+(\mathrm{j}-\mathrm{O}-\mathrm{j})=2(\mathrm{i}-\mathrm{O}-\mathrm{j})
$$

Then the expression for the mixing free energy of the melt can be derived by statistic thermodynamic method.

This paragraph applies the SLAG database of Thermo-calc, to predict a definite range of the composition, with which oxide and sulphide inclusion formed during the deoxidation treatment could be effectively controlled and inhibited.

Since Si and Mn in the steel affect the precipitation of alumina, the inter-relation curve of $\mathrm{Si}$ and Mn contents is calculated and plotted with a macro file which is input to the software. The calculated result can be used as a guide for the metallurgy engineer to select suitable composition of mold steel for plastic in a broad range. For Al contents of $100 \mathrm{ppm}$ and $300 \mathrm{ppm}$ at a given temperature of $1800 \mathrm{~K}$, the calculation results are shown in Fig.8 respectively. The curve in Fig.8 is the calculated critical line of alumina precipitation. When the composition of steel locates at the right side of the curve, alumina does not precipitate and the main inclusion in molten-steel is manganesealuminate. However, if the composition locates at the left side of this curve, the alumina precipitates in molten steel. Thus, the mentioned results are used in the designing of mold steel. 

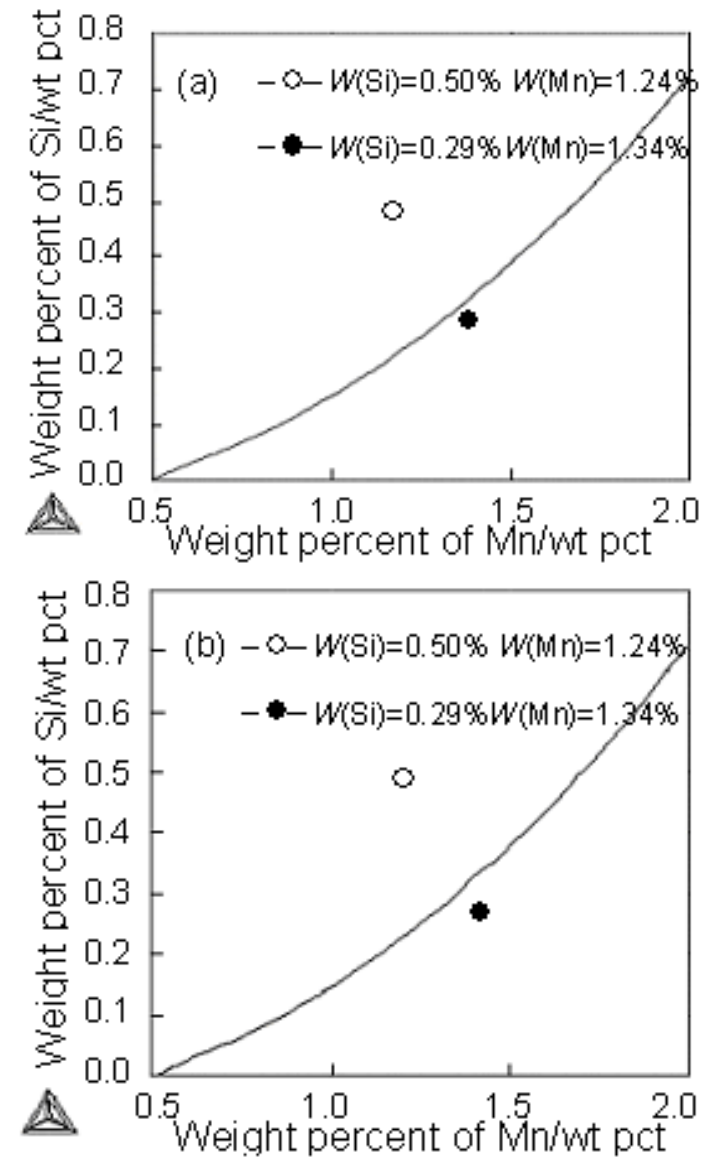

Figure 8. Effect of $\mathrm{Si}$ and $\mathrm{Mn}$ contents on alumina precipitation under $1800 \mathrm{~K}$ for (a) Al content of 100ppm (b) Al content of 300ppm ${ }^{[18]}$

As stated above non-metallic inclusions may appear in molten steel at different stages. Therefore, in addition to the former considerations, the composition of the mold steel is designed in such a way that the oxide inclusion is fixed to be exogenous inclusion, which precipitates before solidification of liquid steel and can be eliminated after slag raking and gas rinsing, or be modified by injecting Ca-Si powder in the ladle. As calculation indicates in Fig.9a, the solidification temperature of the designed steel is $1760 \mathrm{~K}$ while the lowest precipitation temperature of alumina is $1769 \mathrm{~K}$, $9 \mathrm{~K}$ higher than the solidification point meeting well with the design requirement. The same result is obtained in Fig.9b, where the equilibrium phase diagram is calculated with another database of Thermo-calc, showing the solidification point of the steel is $1760 \mathrm{~K}$.

Moreover, the composition is carefully designed to let the driving force of the oxide precipitation be the biggest one following closely by the driving force of MnS. Then, when 
cooling, the alumina precipitates firstly and MnS precipitates afterwards to form the desired structure of good machinability where hard alumina is set in the core and soft MnS outside.

Furthermore, as known, good machining performance connects normally with high homogeneity of microstructures in the steel which is sometimes dependent on annealing process. With Thermo-calc, the main type of carbide which exists in the mold steel but can be dissolved during annealing is designed through the modification of steel composition considerately. The designed carbide is in the type of $\mathrm{M}_{7} \mathrm{C}_{3}$, and this prediction is proved by TEM detection. Soaking temperature for dissolving this carbide is estimated as $1220^{\circ} \mathrm{C}$. Then suitable heat treatment process is taken to ensure the high homogeneity and super machinability of the steel after the annealing treatment in steel production.
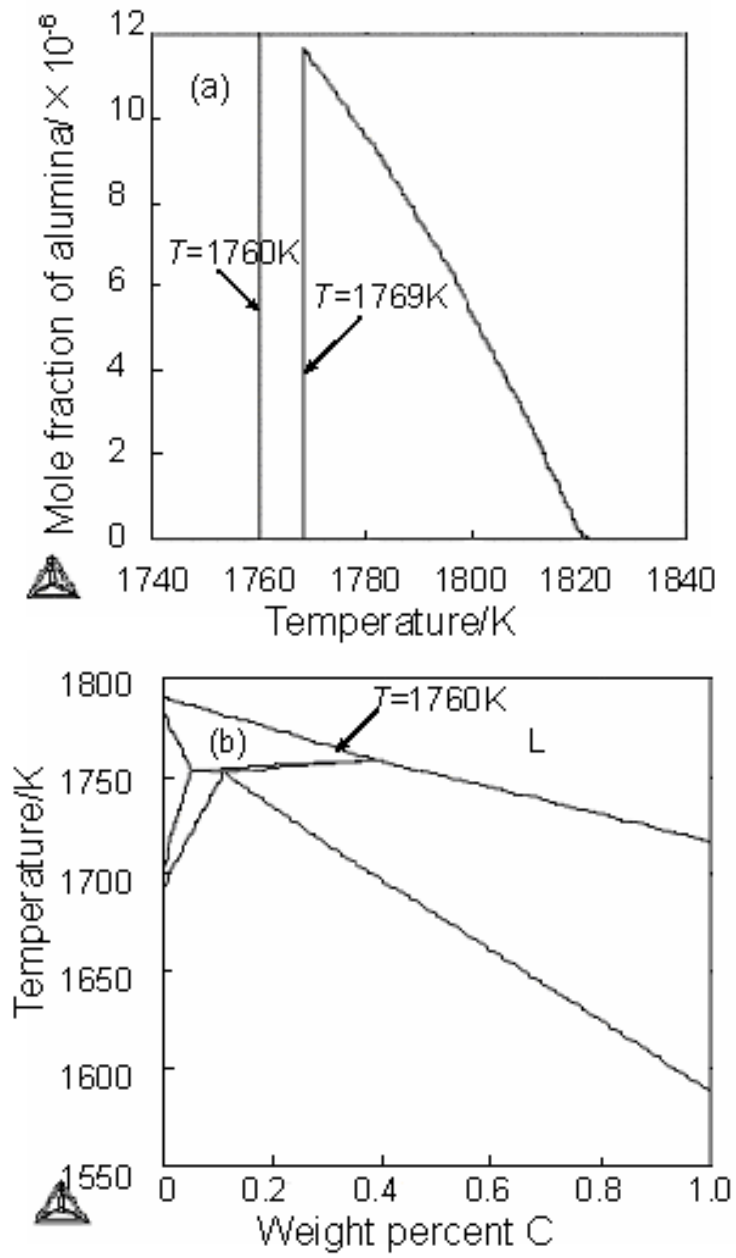

Figure 9. (a) Relationship between the precipitation amount of alumina and temperature in the designed mold steel, solidification temperature being shown (b) phase diagram of the same steel[18] 
Measurement shows the inclusion number in the designed steel is reduced to be less than one tenth of the steel without composition regulation and its machinability reaches the world highest level of mold steel for plastic. The carefully designed mold steel is successfully put into mass production in Baosteel company.

\section{Research and development on the high strength TWIP steel}

Recently TWIP (TWin Induced Plasticity) steel, as one of the most promising advanced HSS (High Strength Steel), was developed showing the highest elongation rate ( $\geqq 80 \%$ ) and fairly good strength $(\approx 600 \mathrm{Mpa})$ due to the effect of TWIP. However, in practical use such as automobile anti-crash parts, the strength seems to be too low but ductility too high. With further consideration of alloy concept, much high strength can be obtained for the steel which comes from hcp martensite transformation. The equilibrium temperature between fcc phase and hcp phase in FeMnSi system and FeMnSiC system has been calculated thermodynamically[20]. It is found that the equilibrium temperature can be adjusted and controlled to be near to the room temperature through rational coordination of $\mathrm{Si}, \mathrm{Mn}$ and $\mathrm{C}$ content in the steel. These results make it possible for realization of strain induced martensite transformation in the steel. However, the $\varepsilon$ (hcp) martensite phase transformation is related to the stacking-fault energy (SFE) in austenite, which is affected by the special characteristics of alloy elements and their interactions and is discussed hereafter ${ }^{[20]}$.

As known, the stacking-fault energy for pure metal can be considered as Gibbs free energy difference between $\gamma$ atoms with two layer of fcc and $\varepsilon$ atoms with two layer of hcp. While for alloy, its Gibbs free energy difference between fcc and hcp close-packed structure is not strictly equal to stacking-fault energy, because the element concentration at stacking faults is different from the average composition of alloy, especially the Suzuki Effect caused by C,N , which leads to the obvious difference of concentrations between stacking faults and base material. So according to the work of Olson and Cohen ${ }^{[21]}$, the thermodynamic model of stacking-fault energy can be expressed as:

$$
\gamma_{\mathrm{SF}}=2 \rho_{\mathrm{A}} \Delta G^{\gamma \rightarrow \varepsilon}+2 \sigma^{\gamma \rightarrow \varepsilon}
$$

Where,

$$
\rho_{\mathrm{A}}=\frac{4}{\sqrt{3}} \frac{1}{a^{2} N}
$$

is the bulk density of atomic surface in face-centered cubic, $a$ is the lattice constant of alloy, $N$ is the avogadro's constant $N=6.02 \times 10^{23} . \sigma^{\gamma \rightarrow \varepsilon}$ is the binding energy of phase interface, according to Allain ${ }^{[22],} \sigma^{\gamma \rightarrow \varepsilon}=(5 \sim 15) \mathrm{mJ} / \mathrm{m}^{2}$. For simplicity, an average, i.e., $10 \mathrm{~mJ} / \mathrm{m}^{2}$ is taken by Li et al in their calculation ${ }^{[20]} . \Delta G^{\gamma \rightarrow \varepsilon}$ is the free energy difference between face-centered cubic $(\gamma)$ and close-packed hexagonal $(\varepsilon)$. Referring to Dumay ${ }^{[23]}$, this part can be expressed as: 


$$
\Delta G^{\gamma \rightarrow \varepsilon}=\Delta G_{\mathrm{FeMnSu}}^{\gamma \rightarrow \varepsilon}+\Delta G_{\mathrm{FeMnSu} / \mathrm{C}}^{\gamma \rightarrow \varepsilon}+\Delta G_{\mathrm{mg}}^{\gamma \rightarrow \varepsilon}
$$

Where, the first item in the right part of the equation represents the effect of main elements such as Fe, Mn and Si on transformation free energy, denoted as:

$$
\Delta G_{\mathrm{FeMnSu}}^{\gamma \rightarrow \varepsilon}=\sum_{i} \Delta G_{i}^{\gamma \rightarrow \varepsilon}+\chi_{\mathrm{Fe}} \chi_{\mathrm{Mn}}\left[C+D\left(\chi_{\mathrm{Fe}}-\chi_{\mathrm{Mn}}\right)\right]+\chi_{\mathrm{Fe}} \chi_{\mathrm{Si}}\left[E+F\left(\chi_{\mathrm{Fe}}-\chi_{\mathrm{Si}}\right)\right]
$$

Where $\Delta G_{i}^{\gamma \rightarrow \varepsilon}$ is the transformation free energy difference of $\gamma \rightarrow \varepsilon$ in pure components $i$. $\chi_{i}$ is the mole fraction of element $i, \mathrm{~T}$ is temperature in Kelvin, the last two items in equation (13) represent the interaction between $\mathrm{Fe}-\mathrm{Mn}$ and $\mathrm{Fe}-\mathrm{Si}$, where the interaction between $\mathrm{Fe}$ and other elements as well as the mutual action of alloy elements can be neglected. The parameters of C, D, E, F in equation (13) were obtained form the corresponding curve fitting and listed in Table 4 after Dumaya et al ${ }^{[23]}$. The $\Delta G_{\mathrm{FeMnSu} / \mathrm{C}}^{\gamma \rightarrow \varepsilon}$ in equation (12) represents effect of interaction between all the substitute elements and carbon on the transformation free energy, which is:

$$
\Delta G_{\mathrm{FeMnSu} / \mathrm{C}}^{\gamma \rightarrow \varepsilon}=\frac{a}{X_{\mathrm{C}}}\left(1-e^{-b X_{\mathrm{C}}}\right)+c X_{\mathrm{Mn}}
$$

While in equation (12), $\Delta G_{\mathrm{mg}}^{\gamma \rightarrow \varepsilon}$ is the mole magnetic free energy difference between $\gamma$ phase and $\varepsilon$ phase, which is:

$$
\Delta G_{\mathrm{mg}}^{\gamma \rightarrow \varepsilon}=G_{m}^{\varepsilon}-G_{m}^{\gamma}
$$

$G_{m}^{\varepsilon}, G_{m}^{\gamma}$ represents respectively the mole magnetic free energy ${ }^{[24-26]}$ of $\gamma$ phase and $\varepsilon$ phase, which is:

$$
G_{m}^{\varphi}=R T \ln \left(\frac{\beta^{\varphi}}{\mu_{B}}+1\right) f^{\varphi}\left(\tau^{\varphi}\right)
$$

Where:

$$
f^{\varphi}\left(\tau^{\varphi}\right)=1-\frac{1}{D}\left\{\frac{79 \tau^{-1}}{140 p}+\frac{474}{497}\left[\frac{1}{p}-1\right]\left[\frac{\tau^{3}}{6}+\frac{\tau^{9}}{135}+\frac{\tau^{15}}{600}\right]\right\}\left(\tau=\frac{T}{T_{C}^{\varphi}} \leq 1\right)
$$

Or:

$$
f^{\varphi}\left(\tau^{\varphi}\right)=-\frac{1}{D}\left[\frac{\tau^{-5}}{10}+\frac{\tau^{-15}}{315}+\frac{\tau^{-25}}{1500}\right]\left(\tau=\frac{T}{T_{C}^{\varphi}}>1\right), b u t D=\frac{518}{1125}+\frac{11692}{15975}\left(\frac{1}{p}-1\right)
$$

as for fcc and hcp crystal structure, $\mathrm{p}=0.28$, for other structure, $\mathrm{p}=0.5$. 


$$
\begin{aligned}
T_{N}^{\gamma} & =250 \ln \left(x_{M n}\right)-4750 x_{C} x_{M n}-22 x_{C u}-2.6 x_{C r}-6.2 x_{S i}+720(K) \\
T_{N}^{\varepsilon} & =580 x_{M n}(K)
\end{aligned}
$$

\begin{tabular}{|c|c|}
\hline$\Delta G_{\mathrm{Fe}}^{\gamma \rightarrow \varepsilon}$ & $-2243.38+4.309 \mathrm{~T} \mathrm{Jmol} \mathrm{Jm}^{-1}$ \\
\hline$\Delta G_{M n}^{\gamma \rightarrow \varepsilon}$ & $-1000.00+1.123 \mathrm{~T} \mathrm{Jmol}^{-1}$ \\
\hline$\Delta G_{\mathrm{Fe} M \mathrm{n}}^{\gamma \rightarrow \varepsilon}$ & $\mathrm{C}=1246 \mathrm{Jmol}^{-1}, \mathrm{D}=-717 \mathrm{Jmol}^{-1}$ \\
\hline$\Delta G_{\mathrm{Fe} M n x / C}^{\gamma \rightarrow \varepsilon}$ & $\mathrm{a}=1246$ Jmol-1, $\mathrm{b}=24.29$ Jmol-1, $\mathrm{c}=17175$ Jmol-1 \\
\hline$\beta^{\gamma} / \mu_{B}$ & $0.7 x_{F \mathrm{e}}+0.62 x_{M n}-0.64 x_{F e} x_{M n}-4 x_{C} \mathrm{Jmol}^{-1}$ \\
\hline$\beta^{\varepsilon} / \mu_{B}$ & $0.62 x_{M n}-4 x_{C} \mathrm{Jmol}^{-1}$ \\
\hline$\Delta G_{A 1}^{\gamma \rightarrow \varepsilon}$ & $2800+5 \mathrm{~T} \mathrm{Jmol}^{-1}$ \\
\hline$\Delta G_{S i}^{\gamma \rightarrow \varepsilon}$ & $-560-8 \mathrm{~T} \mathrm{Jmol}^{-1}$ \\
\hline$\Delta G_{F e S i}^{\gamma \rightarrow \varepsilon}$ & $\mathrm{E}=2850 \mathrm{Jmol}^{-1} ; \mathrm{F}=3520 \mathrm{Jmol}^{-1}$ \\
\hline$\Delta G_{V}^{\gamma \rightarrow \varepsilon}$ & $-3500 \mathrm{Jmol}^{-1}$ \\
\hline
\end{tabular}

Table 4. Parameters used in calculation of stacking-fault energy in Fe-Mn-X-C system $(X=S i, A l, V)^{[23]}$

Y.K.Lee et al ${ }^{[27]}$ considered that as for Fe-Mn alloy with $16-24 \% \mathrm{Mn}$, the phase transformation driving force of hcp martensite was $-68 \sim-120 \mathrm{~J} / \mathrm{mol}$. Allain et al[22] thought that for Fe-Mn-C system, if the stacking-fault energy (SFE) was above $12 \mathrm{~mJ} / \mathrm{m}^{2}$, the austenite was easy to induce twins; if the SFE lower than $18 \mathrm{~mJ} / \mathrm{m}^{2}$, austenite easy to induce hcp martensite. The suggestion of Allain et al[22], say, the SFE value between $12 \sim 18 \mathrm{~mJ} / \mathrm{m}^{2}$ is adopted as the value which induces martensite transformation in the TWIP steel. The calculation result for a steel with $18 \%$ Mn but different $\mathrm{Si}$ and $\mathrm{C}$ is shown in Fig.10 where the composition range suitable for the assigned SFE is pointed.

Steels with different Mn,Si and C content but their SFE ranges between $12 \sim 18 \mathrm{~mJ} / \mathrm{m}^{2}$ is calculated and listed in Table $5^{[20]}$.

For designing of the test steel, a value of stacking fault energy in the range of $12 \sim 18 \mathrm{~mJ} / \mathrm{m}^{2}$ is firstly adopted. Besides, the change of carbon content can be used to adjust the size of stacking fault energy while the content of $\mathrm{Mn}$ is to be set as low as possible to be favorable to the line process. Based on the above calculation the composition of the high strength high ductility steel is designed as $16 \sim 22 \% \mathrm{Mn}, 0.3 \sim 0.6 \% \mathrm{C}$ and $0.2 \sim 0.8 \% \mathrm{Si}$. The Gibbs free energy difference between fcc matrix phase (austenite) and hcp martensite in the steels is calculated with a self-made database ${ }^{[28]}$ and, as an example, the difference of two phases in a steel of $18 \% \mathrm{Mn}-0.528 \mathrm{Si}-0.35 \mathrm{C}$ is shown in Fig. 11. It can be seen that the $\mathrm{T}_{0}$ temperature(at which the Gibbs energy of fcc phase equals to hcp phase) is $330 \mathrm{~K}$, if adding $-68 \mathrm{~J} / \mathrm{mol}$ as driving force ${ }^{[27]}$ 
to the difference, the corresponding temperature is $293 \mathrm{~K}$, which means hcp martenisite can be obtained in room temperature.
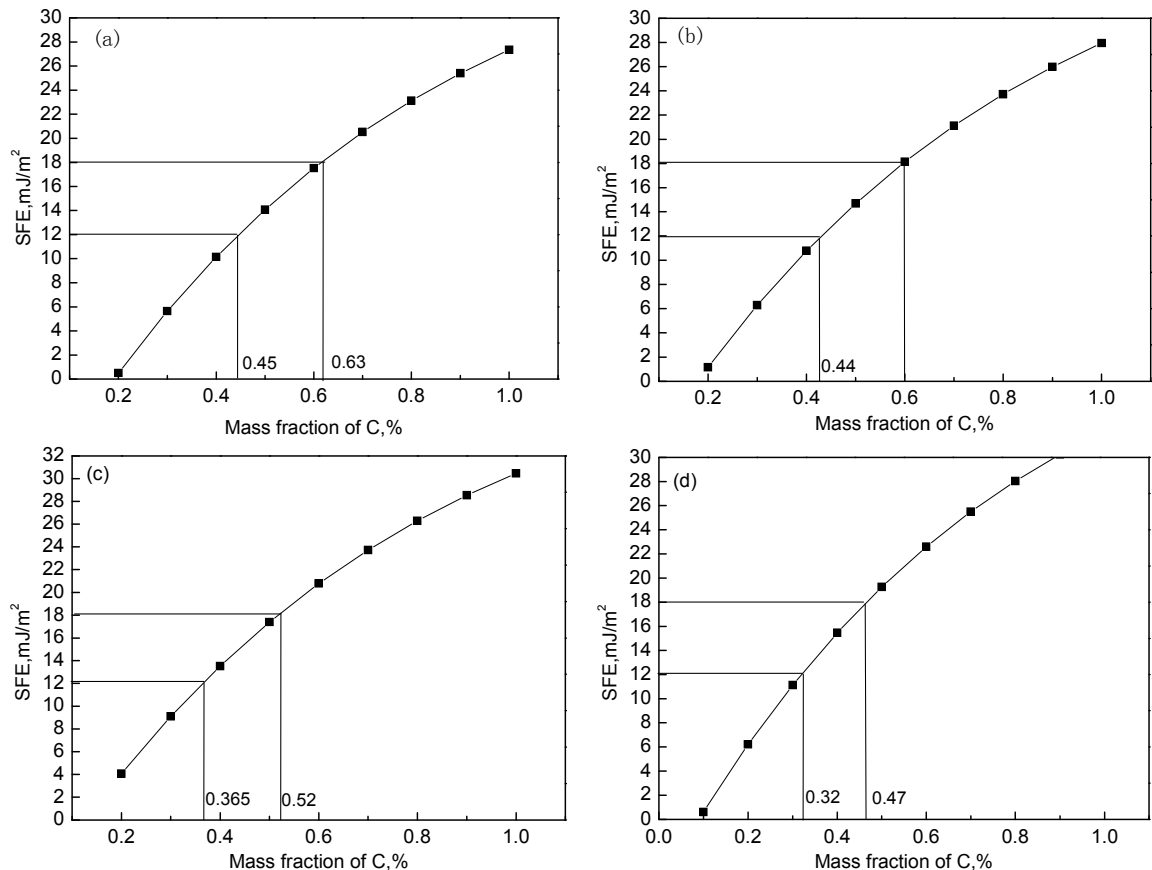

Figure 10. Estimated stacking fault energy(SFE) in Fe-18Mn-YSi-C alloys with $Y=0(a), Y=0.3(b), Y=2(c)$ and $\mathrm{Y}=5(\mathrm{~d}){ }^{[20]}$

\begin{tabular}{llll}
\hline Fe-Mn & $\mathrm{Si}$ & $\mathrm{C}(\mathrm{SFE}=12)$ & $\mathrm{C}(\mathrm{SFE}=18)$ \\
\hline Fe-22Mn & 0 & 0.282 & 0.44 \\
$\mathrm{Fe}-22 \mathrm{Mn}$ & 0.3 & 0.28 & 0.43 \\
Fe-22Mn & 2 & 0.24 & 0.38 \\
Fe-22Mn & 5 & 0.23 & 0.37 \\
Fe-18Mn & 0 & 0.45 & 0.63 \\
Fe-18Mn & 0.3 & 0.44 & 0.6 \\
Fe-18Mn & 2 & 0.365 & 0.52 \\
Fe-18Mn & 5 & 0.32 & 0.47 \\
Fe-15Mn & 0 & 0.55 & 0.73 \\
Fe-15Mn & 0.3 & 0.53 & 0.7 \\
Fe-15Mn & 2 & 0.44 & 0.6 \\
Fe-15Mn & 5 & 0.37 & 0.52 \\
\hline
\end{tabular}

Table 5. Chemical compositions with different SFE(mass fraction, \%) 


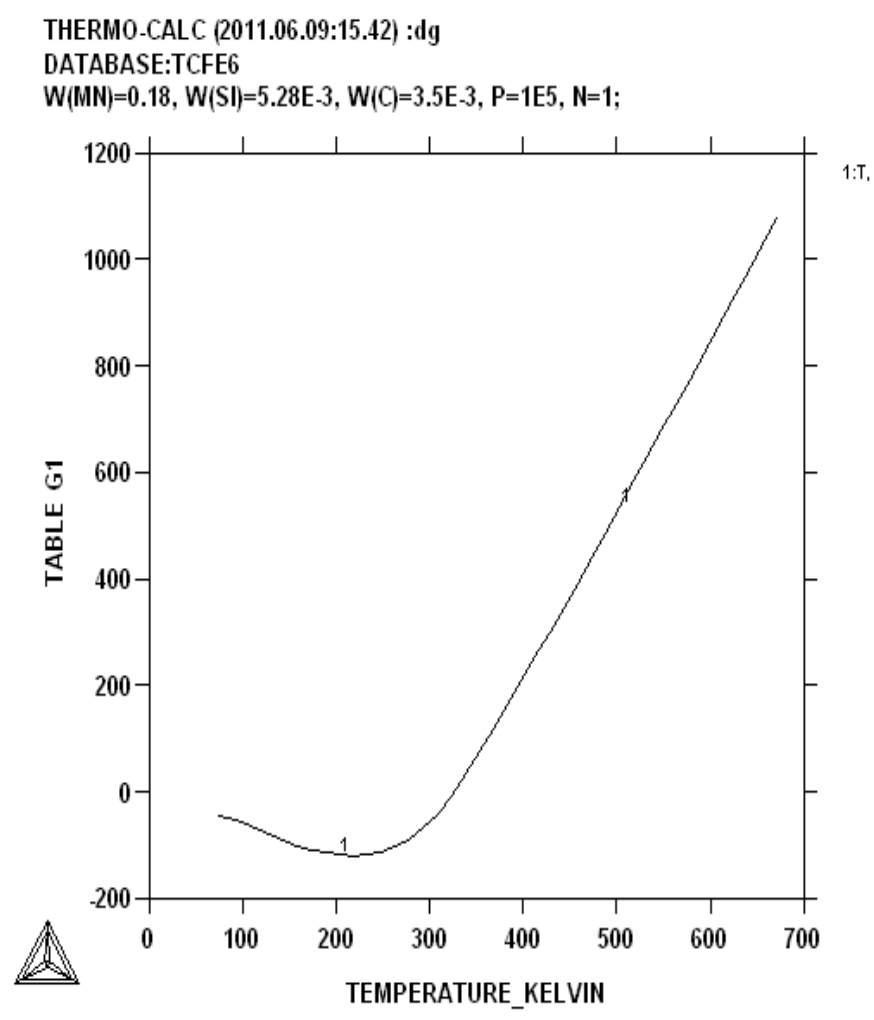

Figure 11. Gibbs free energy difference of two phases $\Delta G^{\gamma \rightarrow \varepsilon}$ in Fe-18Mn-0.528Si-0.35C(mass fraction, \%)steel

The test steel is melt in the $35 \mathrm{~kg}$ vacuum melting furnace and the measured stacking fault energy is $20 \mathrm{~mJ} / \mathrm{m}^{2}$. The ingot is heated up to $1200^{\circ} \mathrm{C}$ and then forged into the stocks with a thickness of $25 \mathrm{~mm}$. The stocks are heated at $1100^{\circ} \mathrm{C}$ for $30 \mathrm{~min}$, finally hot rolled into the plates with a thickness of about $1.5 \mathrm{~mm}$ and then quenched in oil. The final specimens are conducted with XRD, metallographic and SEM analyses. XRD spectrum shows weak $\varepsilon-$ martensite peak in the steel. Optical metallography confirms there exists $\varepsilon$-martensite in the steel when the sample is chemical polished and the effect of mechanical grinding is removed. SEM topography also indicates thin strips with different orientations which is regarded primarily as $\varepsilon$-martensite. Therefore, as revealed by calculation, $\varepsilon$-martensite is formed in this high-Mn TWIP steels after oil quenching.

In order to raise the mechanical property of the steel, different heat treatment after hot rolling is applied. Table 6 shows different final rolling temperatures and cooling methods after hot rolling. 


\begin{tabular}{|l|l|l|}
\hline Steel No. & Final hot rolling temp. $/{ }^{\circ} \mathrm{C}$ & Cooling medium \\
\hline Mn18_1 & 850 & water \\
\hline Mn18_2 & 750 & water \\
\hline Mn18_3 & 850 & air \\
\hline
\end{tabular}

Table 6. Final rolling temperatures and cooling methods after hot rolling

Figure 12 shows the XRD spectrum of the test steels treated with different heat treatment methods after hot rolling processes. It can be seen that the microstructure is the combination of austenite and $\varepsilon$-martensite after hot rolling at $850^{\circ} \mathrm{C}$ and water quenching, but the microstructures are austenite alone after treatment by other processes. Figure 13 shows the strain-stress curves of the test steels treated with different processes. It can be seen that air cooling after hot rolling (as Mn18_3 steel) can lead to the best property such as strength above $1 \mathrm{GPa}$ and elongation rate above $60 \%$. To examine the effect of structure on property, the fracture of the steels is analyzed with XRD as shown in Fig. 14. It can be found that $\varepsilon-$ martensite peak is displayed in the fracture of three specimens. Among this peaks, $\varepsilon$ martensite peak in Mn18_3 specimen is the weakest. Thus, according to the XRD results before and after drawing and the result of tensile test, it can be concluded that $\varepsilon$-martensite existed before tensile test as well as a great amount of $\varepsilon$-martensite induced during tensile test may both raise the strength of the steel, while only a bit of induced $\varepsilon$-martensite during tension improves the property much effectively. All those steels exhibit strength higher than $800 \mathrm{MPa}$ caused by martensite transformation.

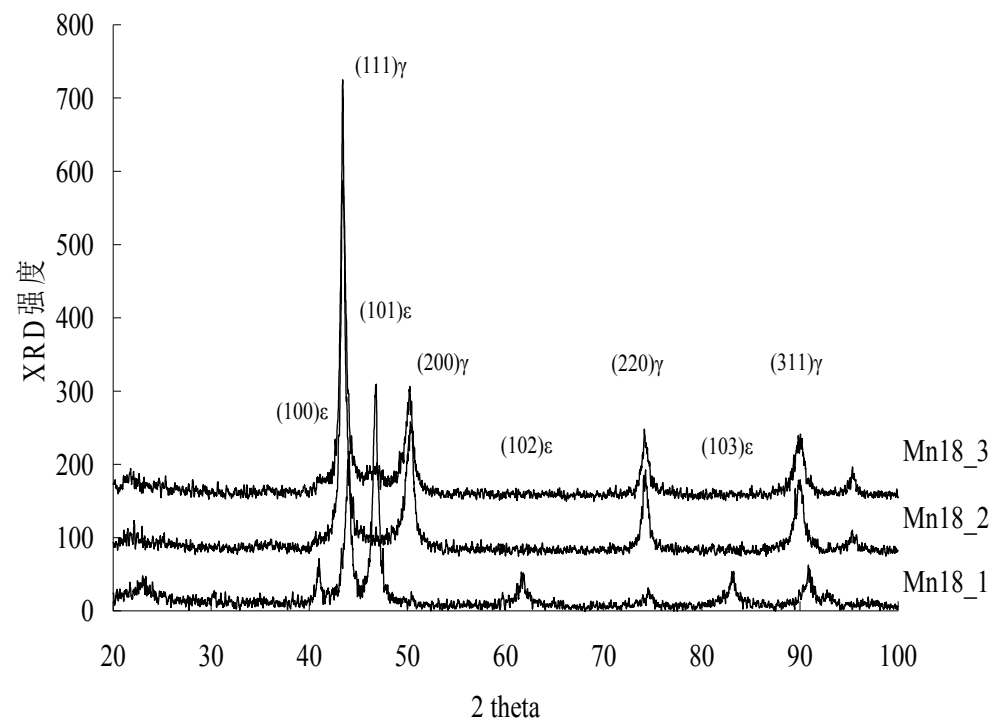

Figure 12. XRD spectra of hot rolling steel 


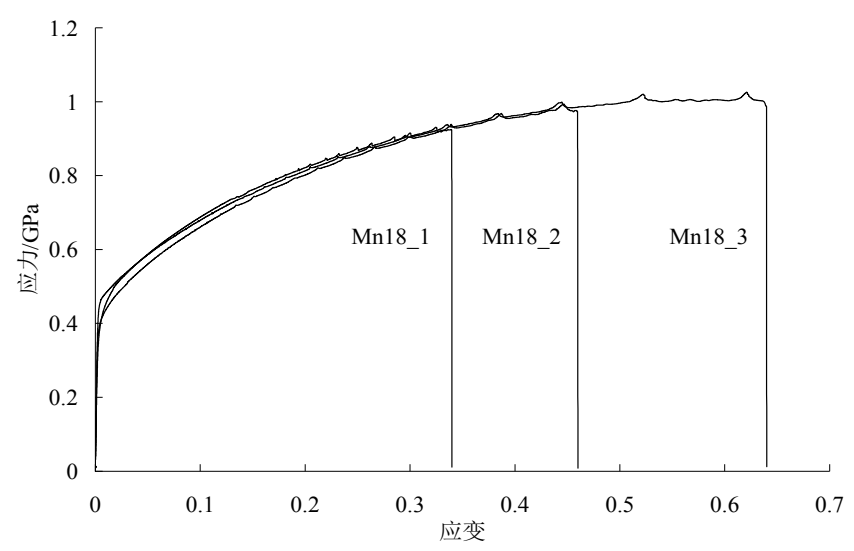

Figure 13. Stress-strain curves of hot rolling steels

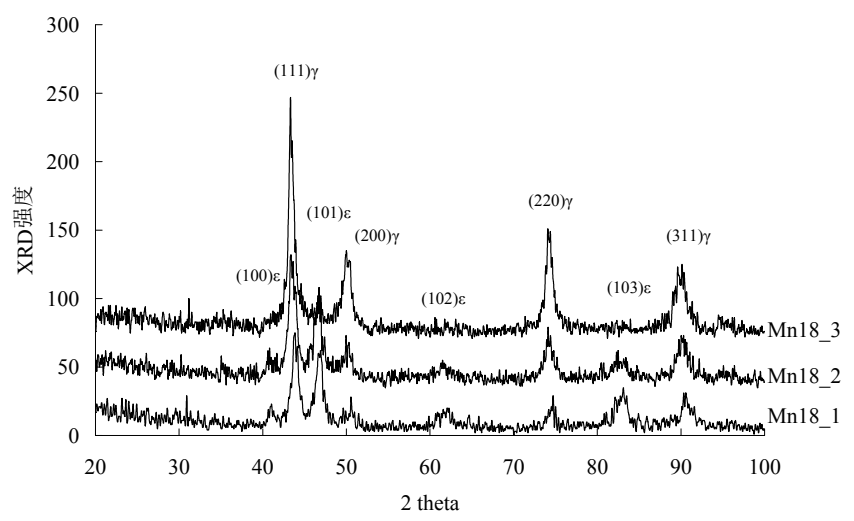

Figure 14. XRD spectra of hot rolling steel after deformation

Combining with the calculation results and experimental process stated above, new type of high strength and ductility TWIP steel is successfully produced in Ansteel group.

\section{Research on high-tech ceramics}

Ceria-doped zirconia ceramics found profound use in automobile emission system recently. When this ceramics is exposed to an inert atmosphere or low oxygen partial pressure at elevated temperature, the $\mathrm{Ce}^{+4}$ will be reduced to $\mathrm{Ce}^{+3}$, a nonstoichiometric phase $\mathrm{Zr}_{1-2} \mathrm{Ce}_{2} \mathrm{O}_{2}$ $\mathrm{x}$ is then formed and the $\mathrm{ZrO}_{2}-\mathrm{CeO}_{2}$ system will convert to a quasi-ternary $\mathrm{ZrO}_{2}-\mathrm{CeO}_{2}-\mathrm{CeO}_{1.5}$ system. It is therefore very useful to study the effect of oxygen partial pressure on the stability of the nonstoichiometric fluorite phase $\mathrm{Zr}_{1-z} \mathrm{Ce}_{2} \mathrm{O}_{2-x}$ in the $\mathrm{ZrO}_{2}-\mathrm{CeO}_{2}-\mathrm{CeO}_{1.5}$ system, which is directly connected to the ability to accumulate or release oxygen of a system, proved to be a guide in producing the high-tech ceramics in the modern industry especially in automobile manufacturing factory. 
In this paragraph, the three limiting binary systems $\mathrm{ZrO}_{2}-\mathrm{CeO}_{2}, \mathrm{ZrO}_{2}-\mathrm{CeO}_{1.5}$ and $\mathrm{CeO} 1.5-\mathrm{CeO}_{2}$ are evaluated with compound energy model[29-31] and substitutional model[32] respectively and the calculation results met well with each other proving the substitutional model is still available to the complex oxide system ${ }^{[33,34]}$.

In $\mathrm{ZrO}_{2}-\mathrm{CeO}_{1.5}$ system ${ }^{[33]}$, compound energy model with structure $\left(\mathrm{Zr}^{+4}, \mathrm{Ce}^{+3}\right)_{1}\left(\mathrm{O}^{-2}, \mathrm{Va}^{0}\right)_{2}$ is used for css phase. The Gibbs energy of one mole of formula unit can be expressed as follows:

$$
\begin{aligned}
G_{m}^{c s s} & =y_{\mathrm{Zr}^{+4}} y_{\mathrm{O}^{-2}}{ }^{o} G_{\mathrm{Zr}^{+4}: \mathrm{O}^{-2}}+y_{\mathrm{Zr}^{+4}} y_{\mathrm{Va}^{0}}{ }^{o} G_{\mathrm{Zr}^{+4}: \mathrm{Va}^{0}} \\
& +y_{\mathrm{Ce}^{+3}} y_{\mathrm{O}^{-2}}{ }^{o} G_{\mathrm{Ce}^{+3}: \mathrm{O}^{-2}}+y_{\mathrm{Ce}^{+3}} y_{\mathrm{Va}^{0}}{ }^{o} \mathrm{G}_{\mathrm{Ce}^{+3}: \mathrm{Va}^{0}} \\
& +R T\left[\left(y_{\mathrm{Zr}^{+4}} \ln y_{\mathrm{Zr}^{+4}}+y_{\mathrm{Ce}^{+3}} \ln y_{\mathrm{Ce}^{+3}}\right)\right. \\
& \left.+2\left(y_{\mathrm{O}^{-2}} \ln y_{\mathrm{O}^{-2}}+y_{V a^{0}} \ln y_{\mathrm{Va}^{0}}\right)\right]+{ }^{E} G_{m}
\end{aligned}
$$

The excess term ${ }^{E} G_{m}$ is given by an equation of the form:

$$
\begin{aligned}
{ }^{E} G_{m}= & y_{\mathrm{Zr}^{+4}} y_{\mathrm{Ce}^{+3}}\left[L_{\mathrm{Zr}^{+4}, \mathrm{Ce}^{+3}: \mathrm{O}^{-2}}\right. \\
& \left.+\left(y_{\mathrm{Zr}^{+4}}-y_{\mathrm{Ce}^{+3}}\right) L_{\mathrm{Zr}^{+4}, \mathrm{Ce}^{+3}: \mathrm{O}^{-2}}^{1}\right]
\end{aligned}
$$

In the $\mathrm{CeO}_{1.5}-\mathrm{CeO}_{2}$ system ${ }^{[33]}$, the nonstoichiometric phase $\left\langle\mathrm{CeO}_{2-\mathrm{y}}\right\rangle$ is described with structure $\left(\mathrm{Ce}^{+4}, \mathrm{Ce}^{+3}\right)_{1}\left(\mathrm{O}^{-2}, \mathrm{Va}^{0}\right)_{2}$. The Gibbs energy of one mole of formula unit can be expressed as follows:

$$
\begin{aligned}
G_{m}^{c s s} & =y_{\mathrm{Ce}^{+4}} y_{\mathrm{O}^{-2}}{ }^{o} G_{\mathrm{Ce}^{+4}: \mathrm{O}^{-2}}+y_{\mathrm{Ce}^{+4}} y_{\mathrm{Va}^{0}}{ }^{o} G_{\mathrm{Ce}^{+4}: \mathrm{Va}^{0}} \\
& +y_{\mathrm{Ce}^{+3}} y_{\mathrm{O}^{-2}}{ }^{o} G_{\mathrm{Ce}^{+3}: \mathrm{O}^{-2}}+y_{\mathrm{Ce}^{+3}} y_{\mathrm{Va}^{0}}{ }^{o} G_{\mathrm{Ce}^{+3}: \mathrm{Va}^{0}} \\
& +R T\left[\left(y_{\mathrm{Ce}^{+4}} \ln y_{\mathrm{Ce}^{+4}}+y_{\mathrm{Ce}^{+3}} \ln y_{\mathrm{Ce}^{+3}}\right)\right. \\
& \left.+2\left(y_{\mathrm{O}^{-2}} \ln y_{\mathrm{O}^{-2}}+y_{\mathrm{Va}^{0}} \ln y_{V a^{0}}\right)\right]+{ }^{E} G_{m}
\end{aligned}
$$

The excess term ${ }^{E} G_{m}$ is given as follows:

$$
\begin{aligned}
{ }^{E} G_{m}= & y_{\mathrm{Ce}^{+4}} y_{\mathrm{Ce}^{+3}}\left[L_{\mathrm{Ce}^{+4}, \mathrm{Ce}^{+3}: \mathrm{O}^{-2}}\right. \\
& \left.+\left(y_{\mathrm{Ce}^{+4}}-y_{\mathrm{Ce}^{+3}}\right) L_{\mathrm{Ce}^{+4}, \mathrm{Ce}^{+3}: \mathrm{O}^{-2}}\right]
\end{aligned}
$$

In the $\mathrm{ZrO}_{2}-\mathrm{CeO}_{2}$ system ${ }^{[33]}$, the css phase is modeled with two sublattices, $\left(\mathrm{Zr}^{+4}, \mathrm{Ce}^{+4}\right)_{1}\left(\mathrm{O}^{-2}\right)_{2}$. Because the valence of cations and anions can fit the condition of electroneutrality without the addition of any defects. All the limiting binaries are optimized and all the parameters are obtained ${ }^{[33]}$.

When $\mathrm{ZrO}_{2}-\mathrm{CeO}_{2}$ system exposed in reduced atmosphere at high temperature, part of $\mathrm{CeO}_{2}$ changes to $\mathrm{CeO}_{1.5}$ in css phase. A new nonstoichiometric phase $<\mathrm{Zr}_{1-\mathrm{z}} \mathrm{Ce}_{2} \mathrm{O}_{2-\mathrm{x}}>$ is considered under the conditions. To describe the ionic characteristics of this phase, the compound 
energy model, i.e., $\left(\mathrm{Zr}^{+4}, \mathrm{Ce}^{+3}, \mathrm{Ce}^{+4}\right)_{1}\left(\mathrm{O}^{-2}, \mathrm{Va}^{0}\right)_{2}$ is also applied to this phase. Based on the parameters of phase css in the three sub-binary oxides system, The Gibbs free energy of one mole phase is ${ }^{[33]}$ :

$$
\begin{aligned}
G_{m}^{c s s} & =y_{\mathrm{Zr}^{+4}} y_{\mathrm{O}^{-2}}{ }^{o} G_{\mathrm{Zr}^{+4}: \mathrm{O}^{-2}}+y_{\mathrm{Zr}^{+4}} y_{\mathrm{Va}^{0}}{ }^{o} G_{\mathrm{Zr}^{+4}: \mathrm{Va}^{0}} \\
& +y_{\mathrm{Ce}^{+3}} y_{\mathrm{O}^{-2}}{ }^{o} G_{\mathrm{Ce}^{+3}: \mathrm{O}^{-2}}+y_{\mathrm{Ce}^{+3}} y_{\mathrm{Va}^{0}}{ }^{o} G_{\mathrm{Ce}^{+3}: \mathrm{Va}^{0}} \\
& +y_{\mathrm{Ce}^{+4}} y_{\mathrm{O}^{-2}}{ }^{o} G_{\mathrm{Ce}^{+4}: \mathrm{O}^{-2}}+y_{\mathrm{Ce}^{+4}} y_{\mathrm{Va}^{0}}{ }^{o} G_{\mathrm{Ce}^{+4}: \mathrm{Va}^{0}} \\
& +R T\left[\left(y_{\mathrm{Zr}^{+4}} \ln y_{\mathrm{Zr}^{+4}}+y_{\mathrm{Ce}^{+3}} \ln y_{\mathrm{Ce}^{+3}}\right.\right. \\
& \left.+y_{\mathrm{Ce}^{+4}} \ln y_{\mathrm{Ce}^{+4}}\right)+2\left(y_{\mathrm{O}^{-2}} \ln y_{\mathrm{O}^{-2}}\right. \\
& \left.\left.+y_{\mathrm{Va}^{0}} \ln y_{\mathrm{Va}^{0}}\right)\right]+{ }^{E} G_{m}
\end{aligned}
$$

The excess term ${ }^{E} G_{m}$ is represented by:

$$
\begin{aligned}
{ }^{E} G_{m}= & y_{\mathrm{Zr}^{+4}} y_{\mathrm{Ce}^{+3}}\left[L_{\mathrm{Zr}^{+4}, \mathrm{Ce}^{+3}: \mathrm{O}^{-2}}^{0}+\left(y_{\mathrm{Zr}^{+4}}-y_{\mathrm{Ce}^{+3}}\right)\right. \\
& \left.L_{\mathrm{Zr}^{+4}, \mathrm{Ce}^{+3}: \mathrm{O}^{-2}}^{1}\right]+y_{\mathrm{Ce}^{+4}} y_{\mathrm{Ce}^{+3}}\left[L_{\mathrm{Ce}^{+4}, \mathrm{Ce}^{+3}: \mathrm{O}^{-2}}\right. \\
& \left.+\left(y_{\mathrm{Ce}^{+4}}-y_{\mathrm{Ce}^{+3}}\right) L_{\mathrm{Ce}^{+4}, \mathrm{Ce}^{+3}: \mathrm{O}^{-2}}^{1}\right]+y_{\mathrm{Zr}^{+4}} y_{\mathrm{Ce}^{+4}} \\
& {\left[L_{\mathrm{Ce}^{+4}, \mathrm{Zr}^{+4}: \mathrm{O}^{-2}}^{0}+\left(y_{\mathrm{Ce}^{+4}}-y_{\mathrm{Zr}^{+4}}\right) L_{\mathrm{Ce}^{+4}, \mathrm{Zr}^{+4}: \mathrm{O}^{-2}}\right] }
\end{aligned}
$$

The calculated phase diagrams and corresponding experimental information of $\mathrm{ZrO}_{2}-\mathrm{CeO}_{2}$, $\mathrm{ZrO}_{2}-\mathrm{CeO}_{1.5}$ and $\mathrm{CeO}_{1.5}-\mathrm{CeO}_{2}$ systems are shown in Fig.15-17[33], where the little circles denote experimental data. In Fig.17, only the miscibility gap is considered in $\mathrm{CeO}_{1.5}-\mathrm{CeO}_{2}$ system. The calculated results met very well with experiments and keep consistent with each other.

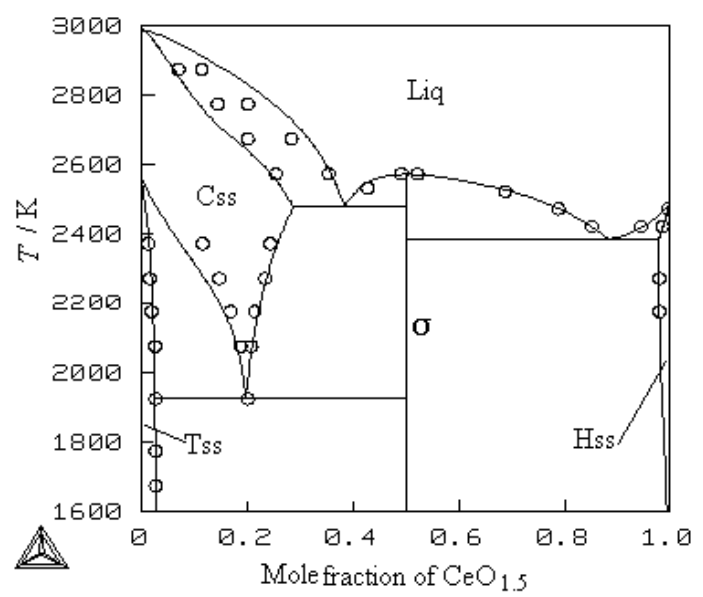

Figure 15. Calculated and experimental phase diagram of $\mathrm{ZrO}_{2}-\mathrm{CeO}_{1.5}$ system, circles showing the experimental result ${ }^{[33]}$ 


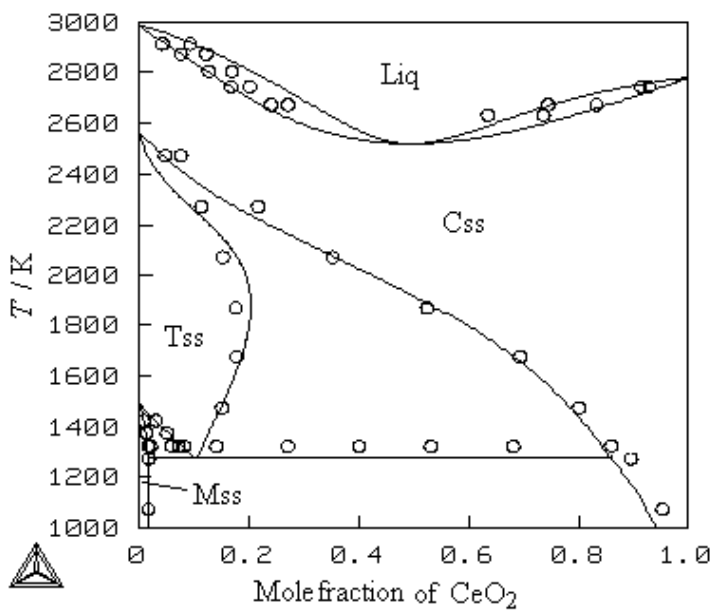

Figure 16. Calculated and experimental phase diagram of $\mathrm{ZrO}_{2}-\mathrm{CeO}_{2}$ system, cycles showing the experimental result ${ }^{[33]}$

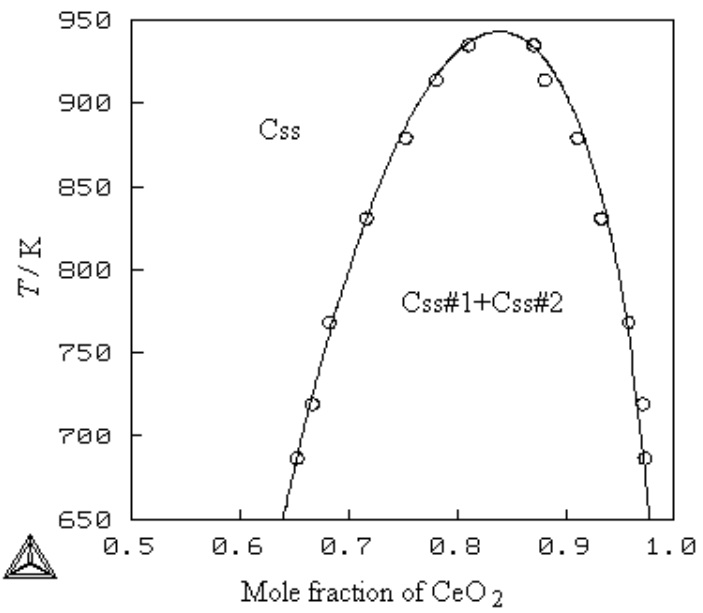

Figure 17. Calculated and experimental miscibility gap in $\mathrm{CeO}_{1.5}-\mathrm{CeO}_{2}$ system, circles showing the experimental result ${ }^{[33]}$

In order to understand thermodynamically the degasing of $\mathrm{CeO}_{2}$, additional deduction is necessary as follows:

The chemical potential of oxygen in phase $\left\langle\mathrm{CeO}_{2-\mathrm{y}}\right\rangle$ depends on the two mass variables, undefected species $\mathrm{CeO}_{2}$ and defected $\mathrm{CeO}_{1.5}$. In $\mathrm{CeO}_{1.5}-\mathrm{CeO}_{2}$ system, it would be natural to list the formula

$$
4 \mathrm{CeO}_{1.5}+\mathrm{O}_{2}=4 \mathrm{CeO}_{2}
$$


With the evaluated model parameters of phase $\left\langle\mathrm{CeO}_{2-\mathrm{y}}\right\rangle$ and Thermo-Calc, The authors ${ }^{[33]}$ get the chemical potential of component $\mathrm{CeO}_{2}$ and $\mathrm{CeO}_{1.5}$ respectively. Therefore, the chemical potential of oxygen in this phase can be listed as:

$$
\mu_{\mathrm{O}_{2}}={ }^{o} \mu_{\mathrm{O}_{2}}+R T \ln \left(\mathrm{PO}_{2}\right)=4 \mu_{\mathrm{CeO}_{2}}-4 \mu_{\mathrm{CeO}_{1.5}}
$$

Under reduced atmosphere, phase css in $\mathrm{ZrO}_{2}-\mathrm{CeO}_{2}$ system changes to $\left\langle\mathrm{Zr}_{1-z} \mathrm{Ce}_{\mathrm{z}} \mathrm{O}_{2-\mathrm{x}}\right\rangle$. Since no defects have been introduced in phase css in $\mathrm{ZrO}_{2}-\mathrm{CeO}_{2}$ system, The authors ${ }^{[33]}$ also get oxygen potential for phase $\left\langle\mathrm{Zr}_{1-z} \mathrm{Ce}_{z} \mathrm{O}_{2-\mathrm{x}}\right\rangle$ from Eq. 24. To get the relation between nonstoichiometry y in $\left\langle\mathrm{CeO}_{2-\mathrm{y}}\right\rangle$ and oxygen potential in phase $\left\langle\mathrm{Zr}_{1-z} \mathrm{Ce}_{2} \mathrm{O}_{2-\mathrm{x}}\right\rangle$ in the ternary system at different temperatures, some manipulation has been made. It is supposed that phase $\left\langle\mathrm{Zr}_{1-z} \mathrm{Ce}_{2} \mathrm{O}_{2-\mathrm{x}}\right\rangle$ is composed of $(1-\mathrm{z})$ mole $\mathrm{ZrO}_{2}$ and $\mathrm{z}$ mole $\left\langle\mathrm{CeO}_{2-\mathrm{y}}\right\rangle$. $\left\langle\mathrm{CeO}_{2-\mathrm{y}}\right\rangle$ is composed of $\mathrm{m}_{2}$ mole $\mathrm{CeO}_{2}$ and $\mathrm{m}_{1}$ mole $\mathrm{CeO}_{1.5}$. Then the $\mathrm{O} / \mathrm{Ce}$ ratio is calculated from the ratio $\mathrm{O} /(\mathrm{Ce}+\mathrm{Zr})$

$$
2-y=[2-x-2(1-z)] / z
$$

To obtain the $\ln (\mathrm{y})-\mathrm{T}-\ln \left(\mathrm{PO}_{2}\right)$ relation, one first need to determine the moles, $\mathrm{m}_{\mathrm{i}}$, of each components. These are calculated from the mass-balance for cerium and oxygen, which is

$$
z=m_{2}+m_{1} \text { and } z(2-y)=2 m_{2}+1.5 m_{1}
$$

Which lead to

$$
m_{1}=2 z y, m_{2}=z(1-2 y)
$$

Where $\mathrm{z}=1$ mole represents a system without component $\mathrm{ZrO}_{2}$.

With the thermodynamic parameters of the three sub-binary systems ${ }^{[33]}$ and Eq. 24, the relation $\ln (y)-\ln \left(\mathrm{PO}_{2}\right)$ in $\mathrm{CeO}_{1.5}-\mathrm{CeO}_{2}$ system, as well as in $\mathrm{ZrO}_{2}-\mathrm{CeO}_{1.5}-\mathrm{CeO}_{2}$ system are calculated by Thermo-Calc ${ }^{[33]}$.

Fig. 18-20 shows the calculated results. Fig. 18 represents the experiment data and the calculated relation $\ln (\mathrm{y})-\ln \left(\mathrm{PO}_{2}\right)$ at $1773 \mathrm{~K}, 1573 \mathrm{~K}, 1473 \mathrm{~K}$, where the little circles denote experiment data from Lindemer et al.[35]. It is obvious that the assessed parameters from $\mathrm{CeO}_{2}-\mathrm{CeO}_{1.5}$ system with compound energy model can represent the relations very well.

Fig. 19 reveals the relation between $\mathrm{CeO}_{1.5}$ and $\ln \left(\mathrm{PO}_{2}\right)$ in a system without component $\mathrm{ZrO}_{2}$ $(\mathrm{z}=1)$ at different temperatures, showing temperature has great effect on oxygen partial pressure. In Fig. 20, different solid lines represent different $z$ values $(0.1,0.2,0.3,1.0)$ corresponding to different mole fraction of $\mathrm{ZrO}_{2}(0.9,0.8,0.7,0$ respectively) in the ternary system at $1473 \mathrm{~K}$. It is obvious that the same nonstoichiometry y corresponds to different oxygen partial pressure at different $\mathrm{z}$. Also can be found is the significant effect of $\mathrm{z}$ value (the content of $\mathrm{ZrO}_{2}$ ) on the relation between oxygen partial pressure and nonstoichiometry value. 


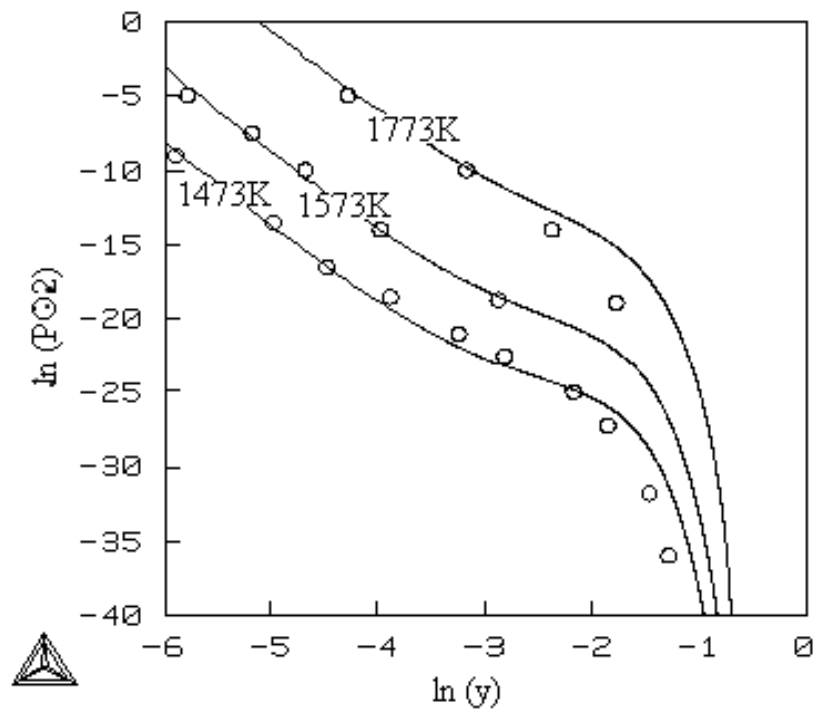

Figure 18. Calculated and experimental relationship $\ln (\mathrm{y})-\ln \left(\mathrm{PO}_{2}\right)$, circles showing the experimental result $[33]$

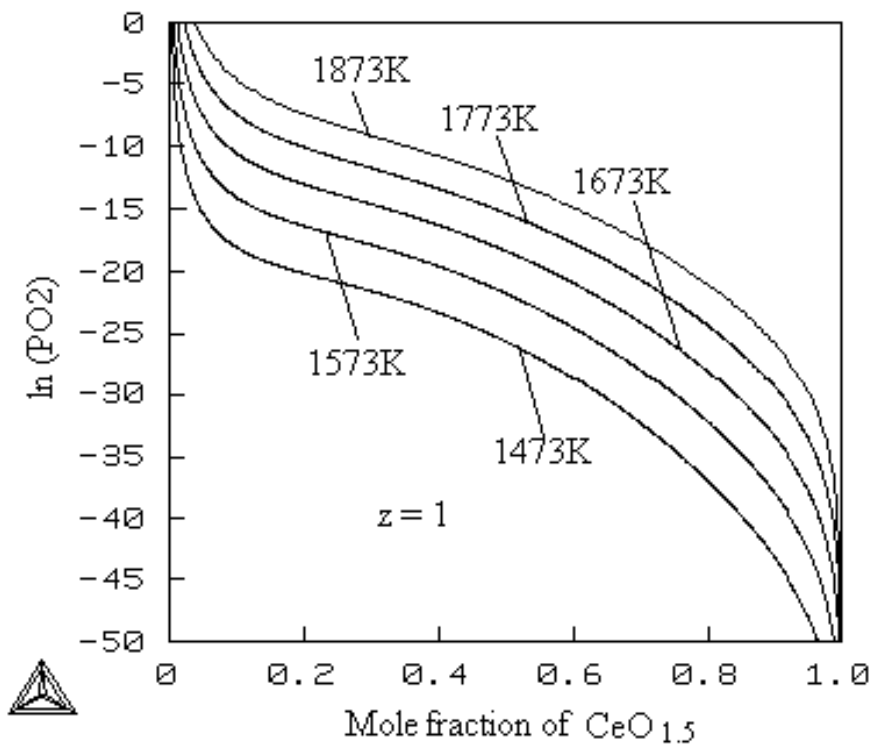

Figure 19. Relations between the different amounts of $\mathrm{CeO}_{1.5}$ and oxygen partial pressure at different temperatures ${ }^{[33]}$ 


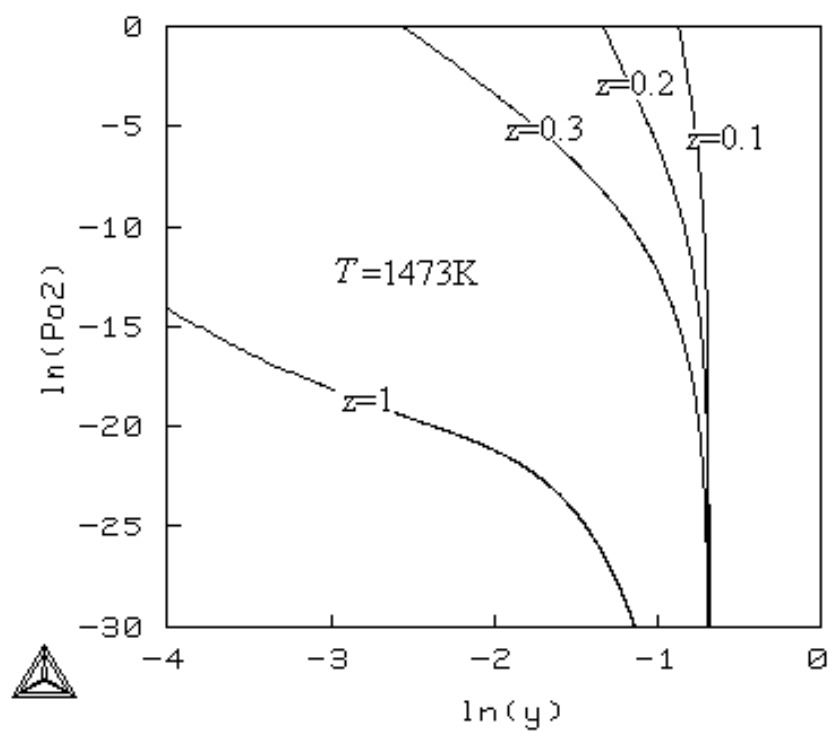

Figure 20. Predicted relations $\ln (\mathrm{y})-\ln \left(\mathrm{PO}_{2}\right)$ at $1473 \mathrm{~K}$ with different $\mathrm{z}$ values ${ }^{[33]}$

A substitutional model was used to describe the quasibinary systems, which estimates the mixing entropy of complex ceramic systems in a very simple way. Kaufman et al ${ }^{[32]} \mathrm{Du}$ et al, ${ }^{[36]}$ and Li et al. ${ }^{[37-39]}$ already successfully evaluated oxide phase diagrams in this way. Li et al ${ }^{[40]}$ pointed:

When calculating oxide systems, if there do not exist any short range ordering, shortage of elements or molecular-like associate in sublattice, the substitutional model is an effective alternative of sublattice model. Furthermore, if the valence of the cations are the same, the application of substitutional model can obtain the same formalism of Gibbs free energy and the same calculated result as that can be obtained by the subblatice model, though the former is more simple and easy to be extened into higher order symtems.

Then, the Gibbs free energy of one mole solution phase, $\Phi$ is described as:

$$
\begin{aligned}
\mathrm{G}_{\mathrm{m}}^{\Phi}(x, T)= & \sum_{i=1}^{2} x_{i} \cdot \Delta^{\circ} G_{f}^{\Phi-i}(T)+R T \sum x_{i} \ln x_{i}+x_{1} x_{2} \\
& \sum_{n=0}^{1} K^{n+3}\left(x_{1}-x_{2}\right)^{n}
\end{aligned}
$$

The first term on the right side accounts for the mechanical mixture of the pure components. $\Delta^{o} G_{f}^{\Phi-i}(T)$ is the standard Gibbs free energy , i.e., the formation energy of mass parameter $i$ from the elements in their standard states. The second term refers to an ideal solution, and the third term is the excess Gibbs free energy function, which is a Redlich-Kister polynomial. The $K^{n}$ factor in Eq. (29) is a temperature-related polynomial and is expressed as: 


$$
K^{n}=A^{n}+B^{n} T+C^{n} T \ln T+D^{n} T^{2}+\mathrm{E}^{\mathrm{n}} / T+F^{n} T^{3}
$$

Gibbs free energy of one mole (cation) stoichiometric compound phase with pyrochlore structure is described as:

$$
G(1 / 4) Z r_{2} C e_{2} O_{7}=(1 / 2) \Delta^{\mathrm{O}} G_{f}^{c s s-Z r 0_{2}}+(1 / 2) \Delta^{\circ} G_{f}^{c s s-C e O_{1.5}}+A+B^{*} T
$$

Also with the relationship deduced in Eqs.(23-27), one can find in a system without $\mathrm{ZrO}_{2}$ component i.e., $z=1$ (mole), the mole fraction of $\mathrm{CeO}_{1.5}$ is $\mathrm{N}_{1}=\mathrm{m}_{1} /\left(\mathrm{m}_{1}+\mathrm{m}_{2}\right)$ and the mole fraction of $\mathrm{CeO}_{2}$ is $\mathrm{N}_{2}=\mathrm{m}_{2} /\left(\mathrm{m}_{1}+\mathrm{m}_{2}\right)$. Moreover, $\mathrm{y}=0.5-0.5 \mathrm{~N}_{2}$.

Based on the thermodynamic information of the limiting quasi-binary systems, which is evaluated in reference [34,41] the molar Gibbs free energy of the nonstoichiometric phase $\mathrm{Zr}_{1-z} \mathrm{Ce}_{z} \mathrm{O}_{2-x}$ can be written according to Maggianu ${ }^{[42]}$ as:

$$
\begin{aligned}
& G^{\prime}\left\langle Z r_{1-z} C e_{z} O_{2-x}\right\rangle /\left(m_{1}+m_{2}+m_{3}\right) \\
& \quad=N_{1} \Delta^{\circ} G_{f}^{c s s}-\mathrm{ZrO}_{2}+N_{2} \Delta^{\circ} G_{f}^{c s-C e O_{2}} \\
& \quad+N_{3} \Delta^{\circ} G_{f}^{c s s-Z r O_{2}}+N_{1} R T \ln \left(N_{1}\right)+N_{2} R T \ln \left(N_{2}\right) \\
& \quad+N_{3} R T \ln \left(N_{3}\right)+K_{1,2}^{3} N_{1} N_{2}+K_{1,2}^{4} N_{1} N_{2}\left(N_{1}-N_{2}\right) \\
&+ \\
&+K_{1,3}^{3} N_{1} N_{3}+K_{1,3}^{4} N_{1} N_{3}\left(N_{1}-N_{3}\right)+K_{2,3}^{3} N_{2} N_{3} \\
&+ K_{2,3}^{4} N_{2} N_{3}\left(N_{2}-N_{3}\right)
\end{aligned}
$$

Where $\Delta^{o} G_{f}^{c s s-i}$ is the standard Gibbs free energy of formation of mass parameter $i$ from the elements in their standard states. $\Delta^{o} G_{f}^{c s s}-\mathrm{ZrO}_{2}$ is after the compilation of Pankratz, ${ }^{[43]}$ whereas $\Delta^{o} G_{f}^{c s s-C e O} O_{1.5}$ is retrieved from the quasi-binary phase diagrams ${ }^{[41]} . K_{i, j}^{n}$ is the interaction coefficient, where $\mathrm{n}$ is the order of the Redlich-Kister polynomial and the subscripts $\mathrm{i}$, $\mathrm{j}$ represent the components, i.e., $\mathrm{CeO}_{1.5}=1, \mathrm{CeO}_{2}=2, \mathrm{ZrO}_{2}=3 . \mathrm{N}_{\mathrm{i}}(\mathrm{i}=1,2,3)$ is the molar fraction of $\mathrm{CeO}_{1.5}, \mathrm{CeO}_{2}$ and $\mathrm{ZrO}_{2}$ respectively.

The partial molar free energy for mass parameter $i$ equals to,

$$
\partial\left[G^{\prime}<\mathrm{Zr}_{1-z} C e_{z} \mathrm{O}_{2-x}>\right] / \partial m_{i}=\Delta \bar{G}_{i}
$$

With the equation similar to Eq. 24,

$$
R T \ln \left(\mathrm{Po}_{2}\right)=4 \Delta \bar{G}_{\mathrm{CeO}_{2}}-4 \Delta \bar{G}_{\mathrm{CeO}_{1.5}}
$$

The relationship between $\ln (\mathrm{y})$ and $\ln \left(\mathrm{PO}_{2}\right)$ at $1473 \mathrm{~K}$ is calculated and shown in Fig. 21, which is exactly the same as shown in Fig. 20 calculated by CEM. 


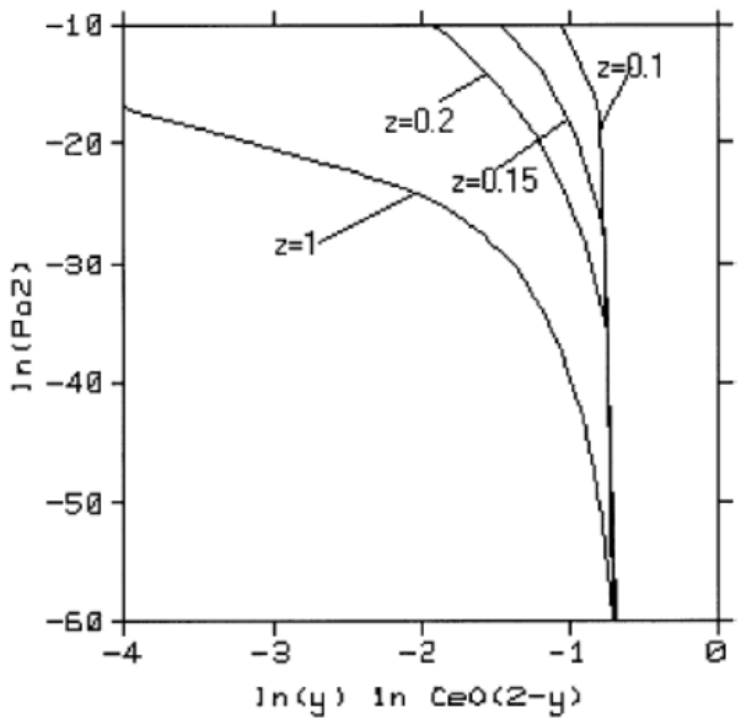

Figure 21. Predicted relationship between $\ln (\mathrm{y})$ and $\ln \left(\mathrm{PO}_{2}\right)$ at $1473 \mathrm{~K}$ at different $\mathrm{CeO}_{2-y}$ molar fractions in the $\mathrm{ZrO}_{2}-\mathrm{CeO}_{2}-\mathrm{CeO}_{1.5}$ system ${ }^{[34]}$

The research staff members in Exhaust System of MERCEDES CAR GROUP checked independently the work stated above over years, they followed each of the published papers and calculated their system with the equations and model parameters in the publications. They were convinced that the calculation stated above predicted the mechanism in the automobile emission system and met very well with their detected data in all the gasoline engines of Mercedes Car.

\section{Conclusion}

An aspiration of engineers in materials field is to have the possibility to estimate in advance the composition, properties, processing parameters, etc., while they are planning to develop a new material. This chapter offers a basic sketch where one could find how thermodynamics, coupled with accurate experiment results, constructs the entrance for mass production. In order to limit the chapter length, only less examples were listed and most of them are stressed at steels, which include developing new type steel, improving the quality of existed steel and discussing the factors mainly influencing steel property. Calculation is applied in the light of the existed commercial software package though, in some cases, suitable derivation to reveal the relationship between thermodynamic properties of substances and self-made database exhibit also extreme importance in the designing of materials. Moreover, both compound energy model and substitutional model are used to describe the complex degassing behavior in the $\mathrm{ZrO}_{2}-\mathrm{CeO}_{2}$ system which reveals how and why the simple model could be successfully applied in complex systems. 


\section{Author details}

Lin $\mathrm{Li}$

School of Materials, Shanghai University, Shanghai, P.R.China

\section{Acknowledgement}

This work is financially supported by National Key Basic Research Development Project of China (973 Programme, No.2010CB630802), NSFC(No.50934011 and No.50971137) and School of Materials, Shanghai University.

\section{References}

[1] Meyer M.D., Vanderschueren D., De Cooman B.C., ISIJ Inter., 1999, 39(8), 813.

[2] Lin Li, B.C. De Cooman, P. Wollants, Yanlin He and Xiaodong Zhou, J Mat. Sci. \& Technol., vol.20,No.2, 135-138, 2004.

[3] Li Lin, Liu Rendong, Shi Wen, Zhang Mei, He Yanlin, Liu Huachu, Fu Renyu, Development of a new type TRIP steel with good weldability and galvanizing property, Proc. 2009 Inter. Symp. automobile steel, Dalian, China, 2009, 332-336.

[4] Guttmann M., Mclean D., Grain Boundary Segregation in Multicomponent Systems, [A] eds. Johnson W.C., Blakely J.M., Interfacial Segregation[M]. Ohio: ASM, Metals Park, 1979. 261-348.

[5] M. Hillert, L.I. Staffansson, Acta Chemica, Scandinavica, 1970, 24, 3618

[6] Li L., Delaey L., Wollants P., O.Van Der Biest, Thermodynamic analysis of the segregation of multicomponent steels[J]. J.Chim. Phys., 1993, 90, 305-312.

[7] Li L., Delaey L., Wollants P., O.Van Der Biest, Thermodynamic Calculation of Segregation in Multicomponent Steels[J]. J.Mater.Sci.\& Technol., 1996, 12(3), 238-240.

[8] Guttmann M., Dumoulin Ph., Wayman M., The thermodynamics of interactive cosegregation of phosphorus and alloying elements in iron and temper-brittle steels[J]. Metall. Trans., 1982, 13A, 1693-1711.

[9] Lin Li, Microstructure and property control of advanced high strength automotive steel, eds., Y.Q.Weng, H.Dong, Y.Gan, Metalluygical Industry Press and Springer, Beijing, 2010, 265

[10] Mclean D., Grain Boundaries in Metals, [M]Oxford: Clarendon Press, 1957.

[11] Sundman B., Jansson B., Andersson J., The thermo-calc databank system[J]. CALPHAD, 1985, 9(2), 153-190.

[12] L. Li, S.G. Huang, L. Wang, Y.L. He, J. Vleugels, O. Van der Biest, Thermodynamic reassessment of the Fe-Al-C system based on the Fe-rich experimental data, Front. Mater. Sci., China, 3(1), 33-37, 2009.

[13] O. Redlich and A.T. Kister, Algebraic Representation of Thermodynamic Properties and the Classification of Solutions, Ind. Eng. Chem. 40 (1948), 345-348. 
[14] Bo Sundman and John Ågren, A regular solution model for phases with several components and sublattices, suitable for computer applications, Journal of Physics and Chemistry of Solids, 42 (4) 1981, 297-301.

[15] K.C.H. Kumar and V. Raghavan, a thermodynamic analysis of the Al-C-Fe system, Journal of Phase Equilibria, 12 (3) (1991), 275-286.

[16] P. Gustafson, A thermodynamic evaluation of the Fe-C system, Scandinavian Journal of Metallurgy, 14 (1985), 259

[17] David K. Matlock, John G. Speer, Third Generation of AHSS, Microstructure Design Concepts,A. Haldar, S. Suwas, and D. Bhattacharjee (eds.), Microstructure and Texture in Steels, (C) Springer 2009,185-205

[18] Yanlin He, Lin Li, Xiaochun Wu, P. Wollants, J Mat. Sci. \& Technol., vol.20, No.1, 71-74, 2004.

[19] H. Gaye, J. Welfringer,Proc.2nd Inter. Conf. Metallurgical Slags \& Fluxes, Lake Tahoe, Nevada, Nov. 1984, 357

[20] Li Lin, Gao Yi, Shi Wen, Liu Rendong, He Yanlin, Fu Renyu, Zhang Mei, Martensite Transformation in High Mn Steels, HMnS2011, Soeal, Korea, A19

[21] G.B. Olson, M. Cohen: Metall. Trans. A, 7A (1976) p. 1897.

[22] S. Allain, J.-P. Chateau, O. Bouaziz, S. Migot, N. Guelton: Materials Science and Engineering A 387-389 (2004) p. 158.

[23] A. Dumaya, J.-P. Chateau, S. Allain, S. Migot, O. Bouaziz: Materials Science and Engineering A 483-484 (2008) p. 184.

[24] Inden G, Metallkde Z. 1977; 68: 529

[25] Hillert M, Jarl M. CALPHAD, 1978; 2: 227

[26] Dinsdale A T. CALPHAD, 1991; 15: 317

[27] Y.K. Lee, C.S.Choi: Metall. Mater. Trans., 31A(2000) p. 355.

[28] LIU Ren-dong, Shi Wen,He Yanlin,Li Lin, ZHANG Xiao-gang, WANG Fu,Designing and Investigating on the Hot Rolling TWIP Steel with TRIP Effect,Acta Metall. Sinica (in Chinese), 2012

[29] T.I. Barry, A.T. Dinsdale, J.A. Gisby, B. Hallstedt, M. Hillert, B. Jansson, S. Jonsson, B. Sundman and J.R. Taylor, J. Phase Equil., 1992, 13,459

[30] M. Hillert, J. Alloys Comp., 2001,320, 161

[31] B. Sundman, J. Alloys Comp., 1991, 12(1), 127

[32] Kaufman, L. and Nesor, H., Calculation of quasi-binary and quasi-ternary oxide systems I. CALPHAD, 1978, 2, 35-53.

[33] Shuigen Huang, Lin Li, O. V. D. Biest, J. Vleugels, Peiling Wang, J Mat. Sci. \& Technol., vol.18, No.5, 422-426, 2002.

[34] Shuigen Huang, Lin Li, Jef Vleugels, Peiling Wang, Omer Van der Biest, Thermodynamic prediction of the nonstoichiometric phase $\mathrm{Zr}_{1-\mathrm{z}} \mathrm{Ce}_{2} \mathrm{O}_{2-\mathrm{x}}$ in the $\mathrm{ZrO}_{2}-$ $\mathrm{CeO}_{1.5}-\mathrm{CeO}_{2}$ system, J. Eur. Ceram. Soc., 23 (2003) 99-106

[35] T.B. Lindemer,J. Brynestad,J. Am. Ceram. Soc., 1986, 69 (12), 867

[36] Du, Y., Yashima, M., Koura, T., Kakihana, M. and Yoshimura,M., Thermodynamic evaluation of the $\mathrm{ZrO}_{2}-\mathrm{CeO}_{2}$ system. Scripta Metall. Mater., 1994, 31, 327-332. 
[37] Li, L., Xu, Z. Y. and Ao, Q., Optimization of the phase diagram of $\mathrm{CeO}_{2}-\mathrm{ZrO}_{2}$ system. J. Mater Sci. Tech., 1996, 12, 159-160.

[38] Li L., Van Der Biest O., Wang P. L., Vleugels J., Chen W. W. and Huang S. G., Estimation of the phase diagram in the $\mathrm{ZrO}_{2}-\mathrm{Y}_{2} \mathrm{O}_{3}-\mathrm{CeO}_{2}$ system. J. Eur. Ceram. Soc., 2001, 21(16), 2903-2910.

[39] Li L., Van Der Biest O., Xu L. P., Vleugels J. and Huang S. G., Prediction of the isothermal sections of the $\mathrm{ZrO}_{2}-\mathrm{Y}_{2} \mathrm{O}_{3}-\mathrm{CeO}_{2}$ system. J. Mater. Sci. Tech., 2001, 17(5), 529534.

[40] Lin Li,O. Van Der Biest,Peiling Wang,Application of Substitutional Model in Oxide System, J.Mater. Sci. Technol., 19(1), 2003, 66

[41] Shuigen Huang, Lin Li, O.V.D. Biest, J. Vleugels, Peiling Wang, Thermodynamic Assessment of the $\mathrm{ZrO}_{2}-\mathrm{CeO}_{2}$ and $\mathrm{ZrO}_{2}-\mathrm{CeO}_{1.5}$ Binary System, J.Mater. Sci. Technol., 18(4), 2002, 325

[42] Muggianu, Y. M., Gambino, M. and Bros, J. P., Enthalpies de formation des alliages liquides bismuth-etain-gallium a 723 K. J. Chim. Phys., 1975, 22, 83-88.

[43] Pankratz, L. B., Thermodynamic Properties of the Elements and Oxides. US Dept. Interior, Bureau of Mines Bulletin 672, US Gov't Printing office, Washington, DC, 1982. 